\title{
Finite Element Modeling of Smart Timoshenko Beams with Piezoelectric Materials
}

\author{
M.A. Elshafei ${ }^{\dagger}$, M.R. Ajala ${ }^{\ddagger}$ and A.M. Riad ${ }^{\ddagger}$
}

\begin{abstract}
In the present work, a finite element model has been proposed to describe the response of isotropic and anisotropic smart beams with piezoelectric materials subjected to different mechanical loads as well as electrical load. The assumed field displacements of the beam are represented by First-order Shear Deformation Theory (FSDT), the Timoshenko beam theory. The equation of motion of the smart beam system is derived using the principle of virtual displacements. A hermit cubic shape function is used to represent the axial displacement $\mathrm{u}$, the transverse displacement is represented by a quadratic shape function, and the normal rotation is represented by a linear shape function and the electric potential at each node. The shear correction factor is used to improve the obtained results. A MATLAB code is developed to compute the natural frequency and the static deformations of the structure system due to the applied mechanical and electrical loads at different boundary conditions. The obtained results obtained of the developed are compared to the available results of other investigators, good agreement is generally obtained.
\end{abstract}

Keywords: Finite element - piezoelectric materials - Timoshenko beam theory - composite materials structure - smart structure system-solid mechanics.

\section{Nomenclature}

\section{Symbol}

A

$A_{i j}$

$\mathrm{B}$

$B_{i j}$

$c_{1}, c_{2}, c_{3}$ and ${ }^{c_{4}}$

$C_{i j k l}$

CBT

$D_{i j}$

$D_{i}$

$d x d y d z$

$\mathrm{E}$

$E_{1}$

$E_{2}$

\section{Definition}

Beam cross section area.

Elements of extensional stiffness matrix.

Width of beam element.

Elements of coupling stiffness matrix.

Constant values.

Elastic constants.

Classical beam Theory.

Elements of bending stiffness matrix.

Electric displacements.

Dimensions of the control volume.

Young's modulus.

Young's modulus in the fiber direction.

Young's modulus in the transversal direction to the fiber.

\footnotetext{
${ }^{\dagger}$ Egyptian Armed Forces, Egypt, maelshafei@yahoo.com .

"Egyptian Armed Forces, Egypt.
} 


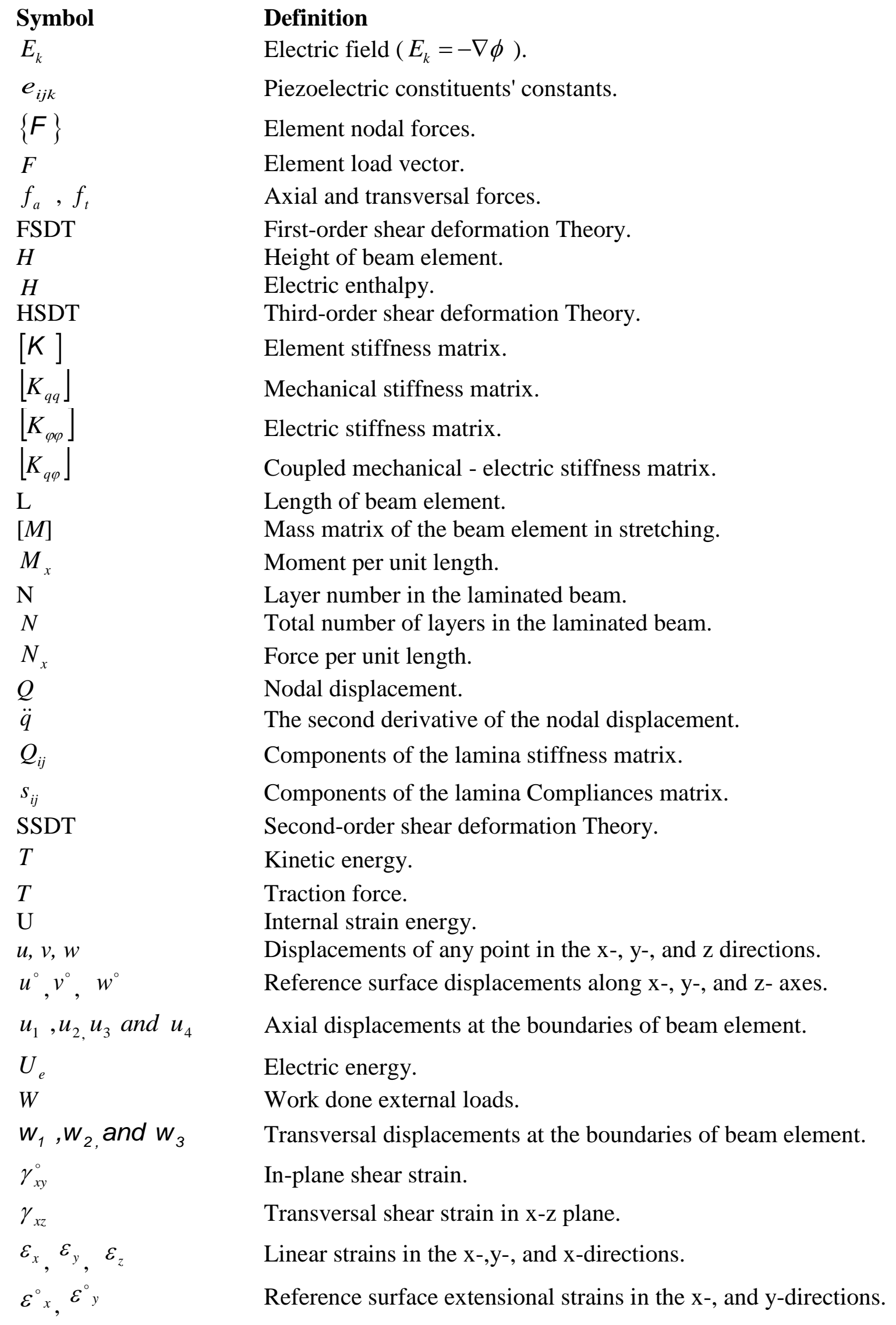




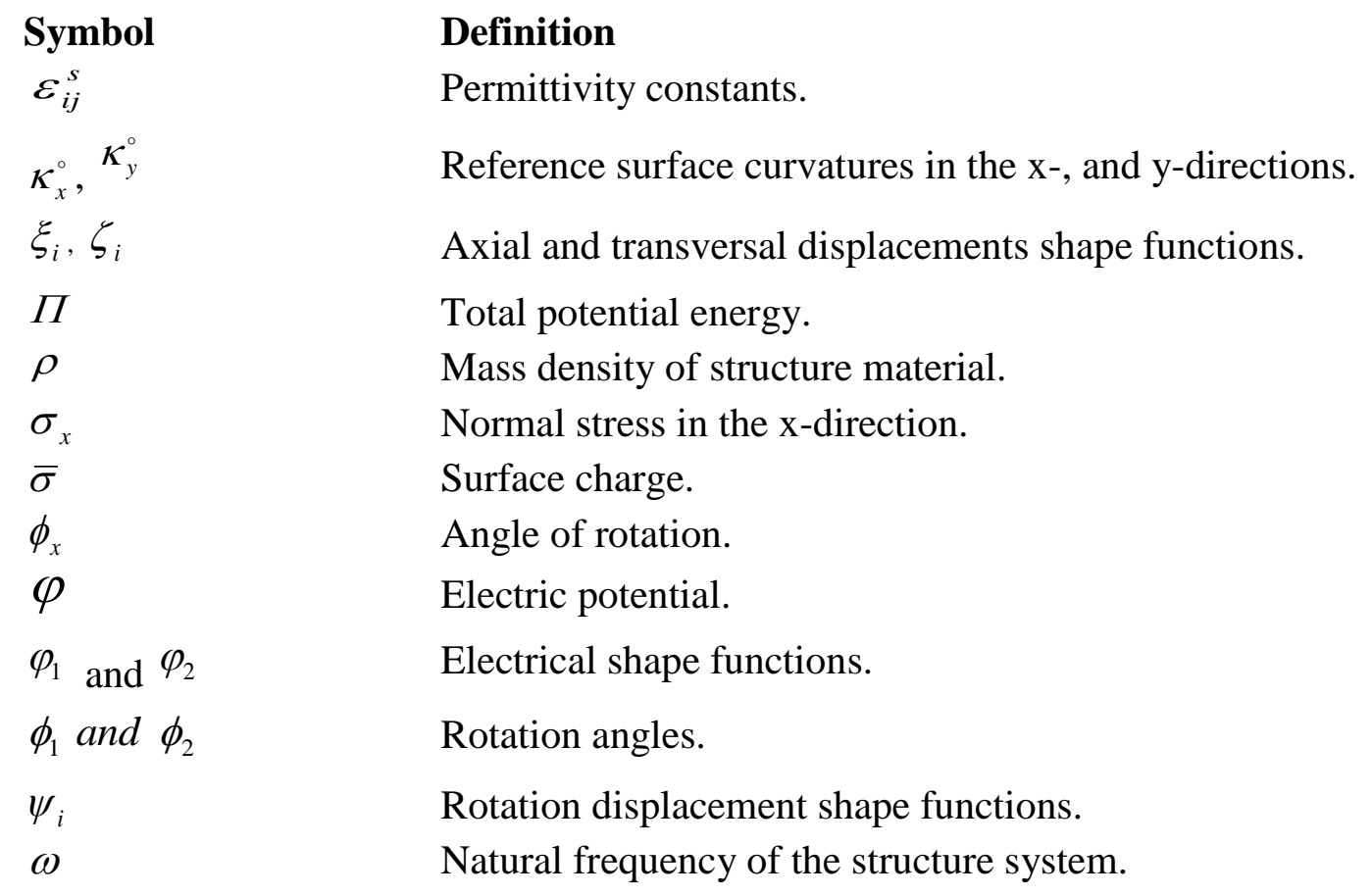

\section{Introduction}

Several researchers are interested in solving the solid and smart beams structures using different theories. They are also interested in considering the shear effects on their results. For solid beam structures, Khdeir and Reddy [1] presented the solution of the governing equations for the bending of cross-ply laminated beams using the state-space concept in conjunction with the Jordan canonical form. They used the classical, the first-order, the second-order, and the thirdorder beam theories in their analysis. They determined the exact solutions for symmetric and asymmetric cross-ply laminated beams with arbitrary boundary conditions subjected to arbitrary loads. They also studied the effect of shear deformation, number of layers, and the orthotropic ratio on the static response of composite beams. They found that the effect of shear deformation caused large differences between the predicted deflections by the classical beam theory and the higher order beam theories, especially when the ratio of beam length to its height was low. They also deduced that the symmetric cross-ply stacking sequence gave a smaller response than those of asymmetric ones. In case of asymmetric cross-ply arrangements, they noticed for the same beam thickness that the beam deflection decreased with increasing the number of beam layers and the orthotropic ratio, respectively.

Yildirim, et al. [2] studied the in-plane free vibration problem of symmetric cross-ply laminated beams based on the transfer matrix method. They considered the rotary inertia, the shear, and the extensional deformation effects on the Timoshenko's beam analysis which gave good results compared to that of other investigators for the natural frequencies associated with the first and higher modes. Nabi and Ganesan [3] studied the free vibration characteristics of laminated composite beams using a general finite element model based on a first-order deformation theory. The model accounted for bi-axial bending as well as torsion. They also studied the effect of beam geometry and boundary conditions on natural frequencies. Their obtained results explained the effect of shear-deformation on vibration frequencies for various angle of ply laminates. 
Chandrashekhara and Bangera [4] developed a finite element model based on a higher-order shear deformation theory with Poisson's effect, in-plane inertia and rotary inertia. They concluded that: (i) the shear deformations decrease the natural frequencies of the beam, which in turn, decrease by increasing the material anisotropy,(ii) the clamped-free boundary condition exhibits the lowest frequencies, (iii) the increase of fiber orientation angle decreases the natural frequency, and (iv) the natural frequencies increase with the increase of the number of beam layers.

For smart beam structures, Henno and Huges [5] used tetrahedral piezoelectric elements for vibration analysis. They introduced the concept of "static condensation of the electric potential degrees of freedom", which presents the electric potential and loads written in terms of the mechanical properties of the structure. Their study was considered as a reference for electroelastic finite element modeling of smart structures.

Crawley and Lazarus [6] studied theoretically and experimentally the induced strain actuation of an intelligent structure. The general procedures for solving the strain energy equations with Rayleigh-Ritz technique were presented. The use of Ritz approximate solutions leaded to understand the system design parameters and to model the smart structure systems. Substantial agreement between the measured and predicted deformations was found. Their obtained results demonstrated that the induced strain actuation was effective for controlling the structure deformation.

Ang k. k., et al. [7] presented analytical solutions determining the length and position of straininduced patch actuators that controlled the static beam deflections. Their solutions were derived using the exact relationships between the bending solutions of the adopted Timoshenko beam theory and the corresponding quantities of the Euler-Bernoulli beam theory. Examples of point deflection control for shear deformable beams subjected to various loads were presented to validate the use of their derived solutions. They discussed the importance of contributing the transverse shear deformation effects on controlling the beam deflection. They predicted that the error resulting due to neglecting the effect of transverse shear deformation represented only a few percent; such a level of accuracy might not be acceptable in applications where very precise control was required, e.g. MEM structures. Similarly, for beams where the shear parameter was substantially large, it would be erroneous to ignore the significant effect of transverse shear deformation.

Clinton, et al. [8] developed a theoretical formulation to model a composite smart structure. Their model was based on a high order displacement field coupled with a layer-wise linear electric potential. They used a finite element formulation with a two node Hermitian element and layer-wise nodes to derive the main equations of motion. They predicted the deflection and curvature of the beam due to the variation of actuator locations and orientations. They deduced the following: (i) the linearity between tip displacement and voltage of piezoelectric polyvinylidene bimorph beam may not necessarily apply on the other structural configurations, (ii) as the substrate stiffness decreases, the obtained actuation increases, (iii) the position of the active actuator near the fixed end of a cantilever has a great effect on beam curvature, (iv) the increase of the actuator numbers can increase the beam deflection and curvature, and (v) the rotation of the substrate 20 degrees around the z-axis results-in increasing the deflection and voltage compared to the un-rotated one, and the greatest effect could achieve by rotating the actuators placed in the middle of the beam. 
Saravanos and Heyliger [9] investigated two separate theories. In the first approach, the transverse displacement component is assumed to be constant through the-thickness; in the second, the transverse displacement is allowed to vary for the inclusion of the interlaminar normal strains and the through-the thickness piezoelectric component. In both approaches, the in-plane displacements and the electrostatic potential is assumed to have arbitrary piecewise linear variations through the thickness of the laminate. The results also indicate the ranges of applicability and limitations of simplified mechanical models of sensory/active composites. Also their predicted natural frequency was in good agreement with that of Robbins and Reddy [10].

Wang and Quek [11] presented the results of dispersion wave propagation curves for beams with surface-bonded piezoelectric patches. They used Euler and Timoshenko models of beam theory. They introduced dispersion curves for different thickness ratios between the piezoelectric layer and the host beam structure. These curves were obtained by assuming a half-cycle cosine potential distribution in the transverse direction of the piezoelectric material. In addition, the phase velocity for wave number was close to infinity, and the cutoff frequencies based on the Timoshenko beam model were also presented. They predicted that the phase velocity decreased as thicker piezoelectric materials were used. In addition, the cutoff frequency was a function of the ratio between the shear and flexural rigidities of the beam.

Zhou Yan-guo, et al. [12] developed an efficient analytical model for piezoelectric bimorph based on the improved First-order Shear Deformation Theory (FSDT). Their model combined the equivalent single-layer approach for mechanical displacements and a layer wise-type modeling of the electric potential. Shear correction factor $\left(k_{s}\right)$ was introduced to modify both the shear stress and the electric displacement of each layer. Excellent agreement between the model predictions with $k_{s}=8 / 9$ and the exact solutions was obtained for the resonant frequencies. The results of their model and their numerical analyses revealed that: (i) piezoelectric bimorphs have similar behavior for series and parallel arrangements under the same loading, (ii) in dynamic analysis, accurate bending vibration frequencies can be obtained by the model even for thick beam (Aspect ratio=5), whereas the classical elastic thin beam theory or plate theory gives low accurate results; (iii) in FSDT model, further investigation is needed for determining the value of shear correction factor of piezoelectric laminates.

Lau, et al. [13] develop a new two-dimensional coupled electro-mechanical model for a thick laminated beam with piezoelectric layer and subjected to mechanical and electric loading. The model combined the first order shear deformation theory for the relatively thick elastic core and linear piezoelectric theory for the piezoelectric lamina. Rayleigh-Ritz method was adopted to model the displacement and potential fields of the beam, and the governing equations were finally derived using the variational energy principle. Their predicted results showed that the electric potential developed across the piezoelectric layer was linear through the thickness and the deflection response of the beam was proportional to the applied voltage.

Bendary, et al. [14] proposed a simple finite element model to describe the behavior of advanced Euler's smart beams with piezoelectric actuators, made of isotropic and/or anisotropic materials, when subjected to axial and transverse loads in addition to electrical load. Both the hermit cubic and Lagrange interpolation functions were used to formulate the finite element for the electroelastic model. The obtained results were compared with the corresponding predictions of other investigators and found reasonable. 
In the present work, a finite element model has been proposed to predict the behavior of advanced smart Timoshenko beams with piezoelectric materials, made of isotropic and/or anisotropic materials, when subjected to axial and transverse loads in addition to electrical load. The constant transverse shear stresses predicted by the used Timoshenko beam theory are always corrected by introducing the shear correction factor. The value of this factor is determined by equating the strain energy due to transverse shear stresses with the strain energy due to the true transverse stresses predicted by the three-dimensional elasticity theory [15]. The equation of motion is derived based on the virtual displacements principle. A MATLAB code is constructed to predict the behavior of advanced beam structure due to different mechanical and electrical loads at different boundary conditions.

\section{Theoretical Formulation}

The displacements field equations of the beam are assumed as [1]:

\begin{tabular}{|c|c|}
\hline$u(x, z)=u_{\circ}(x)-z\left[c_{\circ} \frac{d w}{d x}+c_{1} \phi(x)\right]+c_{2} z^{2} \psi(x)+c_{3}(z / h)^{3}\left[\phi(x)+\frac{d w}{d x}\right]$, & $(1) \mathrm{a}$ \\
\hline$v(x, z)=0$, & $(1) \mathrm{b}$ \\
\hline And & $(1) \mathrm{c}$ \\
\hline
\end{tabular}

where $u, v$ and $w$ are the displacements field equations along the $x, y$ and $z$ coordinates, respectively, $u_{0}$ and $w_{o}$ denote the displacements of a point $(x, y, 0)$ at the mid plane, and $\phi(x)$ and $\psi(x)$ are the rotation angles of the cross-section as shown in Figure (1).

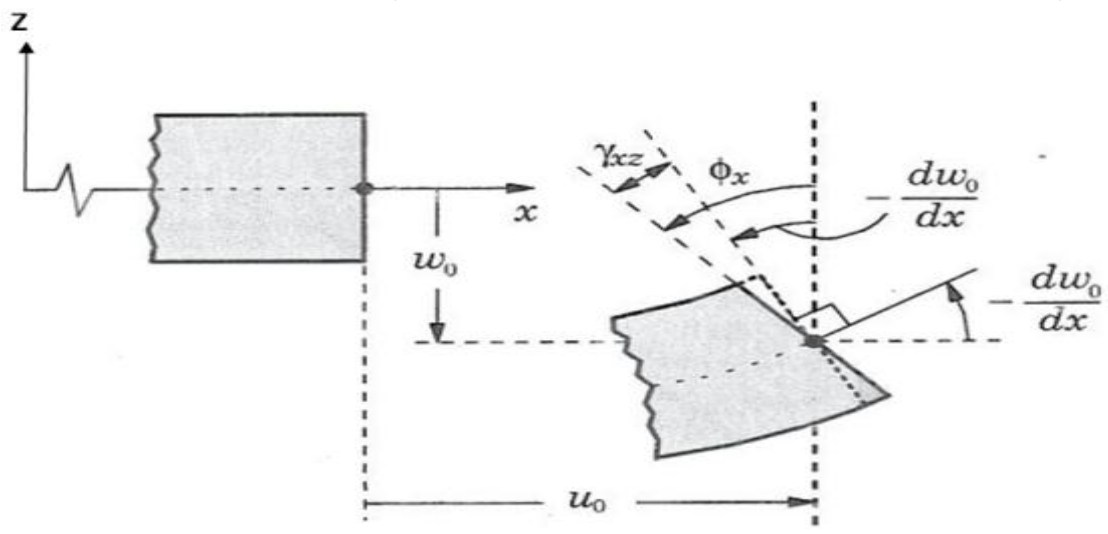

Figure (1): Deformed and un-deformed shape of Timoshenko beam [16].

Selecting the constant values of Eqn. (1)a as: $c_{\circ}=0, \quad c_{1}=1, c_{2}=0, \quad c_{3}=0$, the displacements field equations for Timoshenko first-order shear deformation theory (FSDT) at any point through the thickness can be expressed as [16]:

$$
\begin{aligned}
& u(x, z)=u_{0}(x)-z \phi_{x}(x) \\
& v(x, z)=0 \\
& w(x, z)=w_{\circ}(x)
\end{aligned}
$$


The strain-displacement relationships are obtained by differentiating the assumed displacements field equations, Eqn. (2), and can be represented by:

$$
\begin{gathered}
\varepsilon_{x x}(x, y, z) \equiv \frac{\partial u(x, y, z)}{\partial x}=\frac{\partial u_{\circ}(x, z)}{\partial x}-z \frac{\partial \phi_{x}(x, z)}{\partial x}=\varepsilon_{x x}^{\circ}+z \kappa_{x x}^{\circ} \\
\varepsilon_{y y}(x, y, z) \equiv \frac{\partial v(x, y, z)}{\partial y}=0 \\
\varepsilon_{z z}(x, y, z) \equiv \frac{\partial w(x, y, z)}{\partial z}=0 \\
\gamma_{\mathrm{xz}}(\mathrm{x}, \mathrm{y}, \mathrm{z}) \equiv \frac{\partial \mathrm{u}(\mathrm{x}, \mathrm{y}, \mathrm{z})}{\partial \mathrm{z}}+\frac{\partial \mathrm{w}(\mathrm{x}, \mathrm{y}, \mathrm{z})}{\partial \mathrm{x}}=-\phi_{\mathrm{x}}+\frac{\mathrm{d} \mathrm{w}_{0}}{\mathrm{dx}}=\gamma_{\mathrm{xz}}^{\circ} \\
\gamma_{x y}(x, y, z) \equiv \frac{\partial v(x, y, z)}{\partial x}+\frac{\partial u(x, y, z)}{\partial y}=0 \\
\gamma_{\mathrm{yz}}(\mathrm{x}, \mathrm{y}, \mathrm{z}) \equiv \frac{\partial \mathrm{w}(\mathrm{x}, \mathrm{y}, \mathrm{z})}{\partial \mathrm{y}}+\frac{\partial \mathrm{v}(\mathrm{x}, \mathrm{y}, \mathrm{z})}{\partial \mathrm{z}}=0
\end{gathered}
$$

According to the assumptions of the first order Timoshenko beam theory $\left(\varepsilon_{y y}=\varepsilon_{z z}=\gamma_{x y}=\gamma_{y z}=0\right)$, the only non-zero stress and strain components are $\sigma_{x x}, \sigma_{x z}, \varepsilon_{x x}$, $\gamma_{x z}$ [15]. The strains at any point through the thickness of the beam can be written in matrix form as:

$$
\left\{\begin{array}{l}
\varepsilon_{x x} \\
\gamma_{x z}
\end{array}\right\}=\left\{\begin{array}{l}
\varepsilon_{x x}^{\circ} \\
\gamma_{x z}^{\circ}
\end{array}\right\}+z\left\{\begin{array}{l}
\kappa_{x x}^{\circ} \\
\kappa_{x z}^{\circ}
\end{array}\right\}
$$

Where

$$
\begin{gathered}
\varepsilon_{x x}^{\circ}(x, z)=\frac{\partial u_{\circ}(x, z)}{\partial x} \\
\kappa_{x x}^{\circ}(x, z)=-\frac{\partial \phi_{X}}{\partial x}
\end{gathered}
$$

And

$$
\gamma_{x z}^{(\circ)}(x, z)=-\phi_{x}+\frac{d w \circ}{d x}=\gamma_{x z}
$$

$\varepsilon_{x x}^{\circ}$ is the reference surface extensional strain in the x-direction, $\gamma_{x z}^{\circ}$ is the in-plane shear strain, and $\kappa_{x x}^{\circ}$ is the reference surface curvature in the x-direction. 


\section{Stress-Strain Relations}

\section{Case I: Isotropic Beam}

The stress-strain relation is given as [16]:

$$
\begin{aligned}
& \sigma_{x x}=\mathrm{E} \varepsilon_{x x} \\
& \sigma_{x z}=G \gamma_{x z}=k_{s} G \gamma_{x z}
\end{aligned}
$$

where $k_{s}$ is the shear correction factor.

\section{Case II: Anisotropic Beam}

The stress-strain relation of a lamina in matrix notation is given by [17-18]:

$$
\left\{\begin{array}{l}
\sigma_{x x} \\
\sigma_{x z}
\end{array}\right\}=\left[\begin{array}{ll}
\tilde{Q}_{11} & \\
& k_{s} \tilde{Q}_{55}
\end{array}\right]\left\{\begin{array}{l}
\varepsilon_{x x} \\
\gamma_{x z}
\end{array}\right\}
$$

The complete derivation of Eqn. (7) can be seen in Appendix A.

\section{Piezoelectric Constitutive Relations}

In a linear piezoelectric theory, the electric enthalpy density $H$ is expressed by [19-20]:

$$
H=\frac{1}{2} c_{i j k l} \varepsilon_{i j} \varepsilon_{k l}-e_{k i j} E_{k} \varepsilon_{i j}-\frac{1}{2} \varepsilon^{s}{ }_{i j} E_{i} E_{j}
$$

where $c_{i j k l}, e_{k i j}$, and $\varepsilon_{i j}^{s}$ are the elastic, piezoelectric, and permittivity constants, respectively. By taking the derivatives of Eqn. (8) with respect to the strain and the electric field components there result the piezoelectric constitutive equations [21-22]:

$$
\begin{gathered}
\sigma_{i j}=c_{i j k l} \varepsilon_{k l}-e_{k i j} E_{k} \\
D_{i}=e_{i k l} \varepsilon_{k l}+\varepsilon_{i k}^{s} E_{k}
\end{gathered}
$$

where, $i, j=1, \ldots, 6$ and $k, l=1, \ldots, 3$

Thus, the only non-zero terms in the present model are as follows [23]:

$$
\left\{\begin{array}{l}
\sigma_{x x} \\
\sigma_{x z} \\
D_{z}
\end{array}\right\}=\left[\begin{array}{ccc}
\tilde{Q}_{11} & 0 & 0 \\
0 & k_{s} \tilde{Q}_{33} & 0 \\
\tilde{e}_{31} & 0 & 0
\end{array}\right]\left\{\begin{array}{c}
\varepsilon_{x x} \\
\gamma_{x z} \\
0
\end{array}\right\}-\left\{\begin{array}{c}
\tilde{e}_{31} E_{z} \\
\tilde{e}_{15} E_{x} \\
-\tilde{\varepsilon}_{33}^{s} E_{z}
\end{array}\right\},
$$

where $\mathrm{Q}^{\prime s}$ are given in appendix $\mathrm{A}$, and the piezoelectric coefficients are given by:

$$
\tilde{\varepsilon}_{z z}^{s}=\bar{\varepsilon}_{z z}^{s}+\frac{\bar{e}_{32} \bar{e}_{32}}{\bar{Q}_{22}} \quad \tilde{e}_{31}=\bar{e}_{31}-\bar{e}_{32} \frac{\bar{Q}_{12}}{\bar{Q}_{22}} \quad \tilde{e}_{15}=\bar{e}_{15}-\frac{\bar{e}_{25} \bar{e}_{14}}{\bar{e}_{24}}
$$

The electric field components are related to the electrostatic potential $\varphi$ by the equation:

$$
E_{k}=-\varphi_{k}=-\frac{\partial \varphi}{\partial z}=E_{3} .
$$




\section{Energy Formulation}

The total energy of the structure system is represented by [24]:

$$
\Pi=\hat{U}-U_{e}+W,
$$

where the internal strain energy $\hat{U}$ is represented by [25]:

$$
\hat{U}=\frac{1}{2} \int_{v} \varepsilon_{k l} \sigma_{i j} d v,
$$

and the electric energy $U_{e}$ is expressed by [21-22-26]:

$$
U_{e}=\frac{1}{2} \int_{v} E_{k} D_{i} d v
$$

For an electro-mechanical medium, the internal strain energy for the structure system $U$ is the sum of internal strain energy $\hat{U}$, Eqn. (14), and the electric energy $U_{e}$, Eqn. (15), such as:

$$
U=\int_{v}\left[\frac{1}{2} c_{i j k l} \varepsilon_{i j} \varepsilon_{k l}-e_{k i j} E_{k} \varepsilon_{i j}-\frac{1}{2} \varepsilon_{i j}^{s} E_{i} E_{j}\right] d v
$$

The work done due to the external mechanical and electrical loads represents the sum of the work done by surface traction force $t$, transverse force $f_{t}$, axial forces $f_{a}$, and the surface charge density $\sigma$, and it is expressed by [23-25]:

$$
W=\iint_{R}\left[t u+f_{t} w-\sigma \varphi\right] d x d y+\iint_{R}\left[f_{a} u\right] d x d z
$$

where $\varphi$ is the electric potential.

The mass matrix can be obtained using the kinetic energy which is given by:

$$
T=\frac{1}{2} \int_{v} \rho\left[\dot{u}^{2}+\dot{w}^{2}\right] d v
$$

where, $\rho$ is the mass density of the beam material.

Substituting by the strains components of Eqn. (2) into Eqns. (16), (17), and (18) the equations representing the strain energy, the external work, and the kinetic energy take the following forms:

$$
\begin{gathered}
U=\int_{v}\left[\begin{array}{l}
\left.\frac{1}{2}\left[\tilde{Q}_{11}\left(\frac{\partial u_{0}}{\partial x}-z \frac{\partial \phi_{x}}{\partial x}\right)^{2}+k_{s} \tilde{Q}_{55}\left(-\phi_{x}+\frac{\partial w_{0}}{\partial x}\right)^{2}\right]-\tilde{e}_{31}\left(-\frac{\partial \varphi}{\partial z}\right)\left[\left(\frac{\partial u_{0}}{\partial x}-z \frac{\partial \phi_{x}}{\partial x}\right)+\left(-\phi_{x}+\frac{\partial w_{0}}{\partial x}\right)\right]\right] d v \\
-\frac{1}{2}\left(-\frac{\partial \varphi}{\partial z}\right)^{2}\left(\tilde{\varepsilon}_{33}^{s}\right)
\end{array}\right] \\
W=\iint_{R}\left[t\left(u_{0}-z \phi_{x}\right)+f_{t} w_{0}-\sigma \varphi\right] d x d y+\iint_{R}\left[f_{a}\left(u_{0}\right)\right] d y d z
\end{gathered}
$$

, and

$$
T=\frac{1}{2} \int_{v}\left[\left(\dot{u}_{0}-z \dot{\phi}_{x}\right)^{2}+\left(\dot{w}_{0}\right)^{2}\right] d v
$$

where the surface charge density $\sigma$ is defined as [23]: $\quad \sigma=\frac{\varepsilon_{33}^{s}}{h_{p}} V$. 


\section{Finite Element Formulation}

In formulating the finite element equations, a five nodes beam element with nine mechanical degrees of freedom representing the deformations $\mathrm{u}, \mathrm{w}$, and $\phi$, in addition to two electric degrees of freedom are used as shown in Figure (2). The predicted results of the model are converged and used for calculating the deflection and the natural frequency of the smart beam structure.

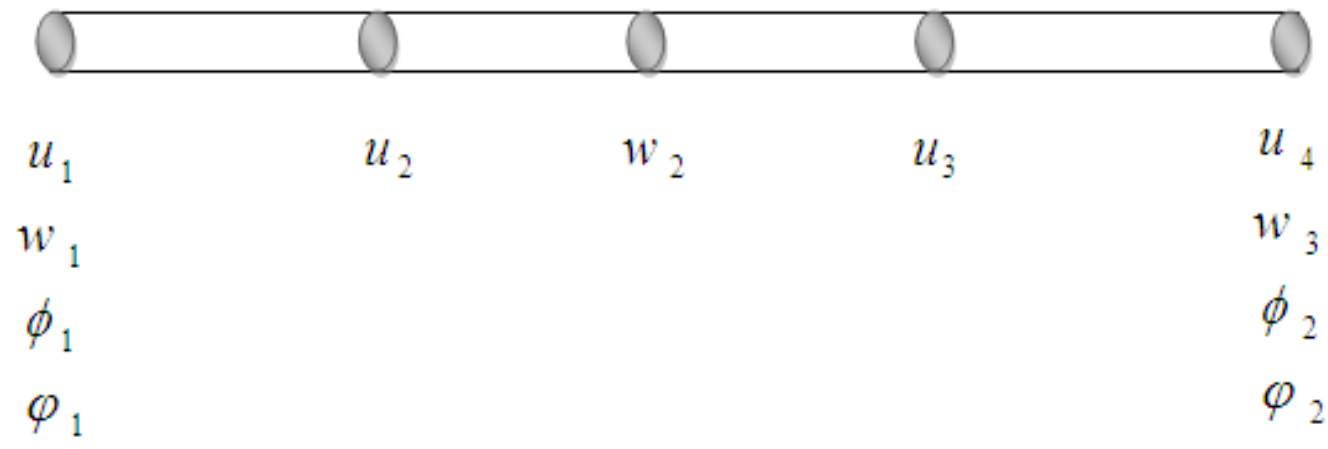

Figure (2): Element with nodal degrees of freedom.

The axial displacement can be expressed in the nodal displacement as follows [16-27]:

$$
u_{0}(x)=u_{1} \xi_{1}+u_{2} \xi_{2}+u_{3} \xi_{3}+u_{4} \xi_{4}=\sum_{j=1}^{4} u_{j} \xi_{j}
$$

The Hermit cubic shape functions $\xi_{j}$ are found to be:

$$
\begin{aligned}
& \xi_{1}=1-3\left(\frac{x}{L}\right)^{2}+2\left(\frac{x}{L}\right)^{3} \\
& \xi_{2}=x-2\left(\frac{x^{2}}{L}\right)+\frac{x^{3}}{L^{2}} \\
& \xi_{3}=3\left(\frac{x}{L}\right)^{2}-2\left(\frac{x}{L}\right)^{3} \\
& \xi_{4}=-\frac{x^{2}}{L}+\frac{x^{3}}{L^{2}}
\end{aligned}
$$

The transversal displacement $w$ can be expressed in terms of the nodal displacement as [28]:

$$
w_{0}(x)=w_{1} \zeta_{1}+w_{2} \zeta_{2}+w_{3} \zeta_{3}=\sum_{j=1}^{3} w_{j} \zeta_{j}
$$

where, the quadratic interpolation shape functions are given by:

$$
\zeta_{1}=1-3\left(\frac{x}{L}\right)+2\left(\frac{x}{L}\right)^{2} \quad \zeta_{2}=4\left(\frac{x}{L}\right)-4\left(\frac{x}{L}\right)^{2} \quad \zeta_{3}=-\left(\frac{x}{L}\right)+2\left(\frac{x}{L}\right)^{2}
$$

The rotation angle $\phi_{x}$ is expressed as [29]:

$$
\phi_{x}(x)=\phi_{1} \psi_{1}+\phi_{2} \psi_{2}=\sum_{j=1}^{2} \phi_{j} \psi_{j}
$$

where the linear interpolation shape functions $\psi_{j}$ have the form:

$$
\psi_{1}=1-\frac{x}{L} \quad, \text { and } \quad \psi_{2}=\frac{x}{L}
$$


For the piezoelectric element, the electric potential function takes the form [30]:

$$
\varphi(z)=\varphi_{1} \varsigma_{1}^{*}+\varphi_{2} \varsigma_{2}^{*}=\sum_{j=1}^{2} \varphi_{j} \varsigma_{j}^{*}
$$

where; $\varsigma_{1}^{*}$ and $\varsigma_{2}^{*}$ are represented by:

$$
\varsigma_{1}^{*}=\frac{1}{2}+\frac{z}{h} ; \quad \varsigma_{2}^{*}=\frac{1}{2}-\frac{z}{h}
$$

The electric potential is considered as a function of the thickness and the length of the beam, thus by the product of equations (27) and (29) and impose the homogenous boundary condition on the bottom surface to eliminate the rigid body modes. The shape functions are finally takes the form [14]:

$$
\varsigma_{1}=\left(\frac{1}{2}+\frac{z}{h}\right)\left(1-\frac{x}{L}\right) ; \varsigma_{2}=\left(\frac{1}{2}+\frac{z}{h}\right)\left(\frac{x}{L}\right)
$$

\section{Variational Formulation}

By applying the principle of the virtual displacements to a representative physical element of the beam, thus,

$$
\delta U=\delta W+\delta T
$$

The first variation of the strain energy, the external work, and the kinetic energy presented in equations (19), (20), and (21) take the forms [25]:

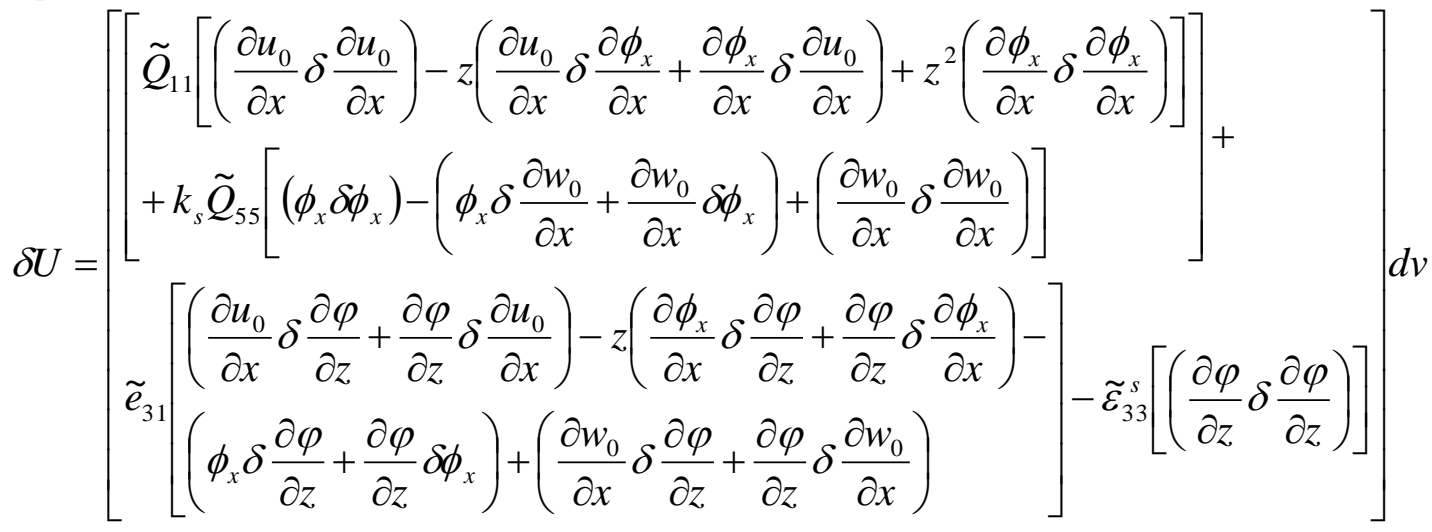

Substituting by Eqns. (22), (24), (26), and (28) into Eqn. (32), one can obtain:

$$
\delta U=\int_{v}\left(H_{1}+H_{2}+H_{3}\right) d v
$$

where, 


$$
H_{1}=\left[\begin{array}{c}
\tilde{Q}_{11}\left[\begin{array}{c}
\left(\sum_{j=1}^{4} u_{j} \frac{d \xi_{j}}{d x} \sum_{i=1}^{4} \delta u_{i} \frac{d \xi_{i}}{d x}\right)-z\left[\sum_{j=1}^{2} \phi_{j} \frac{d \psi_{j}}{d x} \sum_{i=1}^{4} \delta u_{i} \frac{d \xi_{i}}{d x}\right] \\
-z\left[\sum_{j=1}^{4} u_{j} \frac{d \xi_{j}}{d x} \sum_{i=1}^{2} \delta \phi_{i} \frac{d \psi_{i}}{d x}\right]+z^{2}\left[\sum_{j=1}^{2} \phi_{j} \frac{d \psi_{j}}{d x} \sum_{i=1}^{2} \delta \phi_{i} \frac{d \psi_{i}}{d x}\right]
\end{array}\right] \\
+k_{s} \tilde{Q}_{55}\left[\begin{array}{c}
\left(\sum_{j=1}^{2} \phi_{j} \psi_{j} \sum_{i=1}^{2} \delta \phi_{i} \psi_{i}\right)-\left(\sum_{j=1}^{3} w_{j} \frac{d \zeta_{j}}{d x} \sum_{i=1}^{2} \delta \phi_{i} \psi_{i}\right) \\
\left.-\left(\sum_{j=1}^{2} \phi_{j} \psi_{j} \sum_{i=1}^{3} \delta w_{i} \frac{d \zeta_{i}}{d x}\right)+\left(\sum_{j=1}^{3} w_{j} \frac{d \zeta_{j}}{d x} \sum_{i=1}^{3} \delta w_{i} \frac{d \zeta_{i}}{d x}\right)\right]
\end{array}\right]
\end{array}\right]
$$

$$
H_{2}=\tilde{e}_{31}\left[\begin{array}{l}
\left(\sum_{j=1}^{4} u_{j} \frac{d \xi_{j}}{d x} \sum_{i=1}^{2} \delta \varphi_{i} \frac{d \varsigma_{i}}{d z}\right)+\left(\sum_{j=1}^{2} \varphi_{j} \frac{d \varsigma_{j}}{d z} \sum_{i=1}^{4} \delta u_{i} \frac{d \xi_{i}}{d z}\right) \\
-z\left(\sum_{j=1}^{2} \phi_{j} \frac{d \psi_{j}}{d z} \sum_{i=1}^{2} \delta \varphi_{i} \frac{d \varsigma_{i}}{d z}+\sum_{j=1}^{2} \varphi_{j} \frac{d \varsigma_{j}}{d z} \sum_{i=1}^{2} \delta \phi_{i} \frac{d \psi_{i}}{d x}\right) \\
-\left(\sum_{j=1}^{2} \phi_{j} \psi_{j} \sum_{i=1}^{2} \delta \varphi_{i} \frac{d \varsigma_{i}}{d z}\right)-\left(\sum_{j=1}^{2} \varphi_{j} \frac{d \varsigma_{j}}{d z} \sum_{i=1}^{2} \delta \phi_{i} \psi_{i}\right) \\
+\left(\sum_{j=1}^{3} w_{j} \frac{d \zeta_{j}}{d x} \sum_{i=1}^{2} \delta \varphi_{i} \frac{d \varsigma_{i}}{d z}\right)+\left(\sum_{j=1}^{2} \varphi_{j} \frac{d \varsigma_{j}}{d z} \sum_{i=1}^{3} \delta w_{i} \frac{d \zeta_{i}}{d x}\right)
\end{array}\right]
$$

, and

$$
H_{3}=-\widetilde{\varepsilon}_{33}^{s}\left[\sum_{j=1}^{2} \varphi_{j} \frac{d \varsigma_{j}}{d z} \sum_{i=1}^{2} \delta \varphi_{i} \frac{d \varsigma_{i}}{d z}\right]
$$

Using Eqns. (34), (35) and (36), Eqn. (33) takes the following form:

$$
\begin{aligned}
& {\left[\left[\tilde{Q}_{11}\left(\sum_{j=1}^{4} \frac{d \xi_{j}}{d x} \sum_{i=1}^{4} \frac{d \xi_{i}}{d x}\right) u_{j}-\tilde{Q}_{11} z\left(\sum_{j=1}^{2} \frac{d \psi_{j}}{d x} \sum_{i=1}^{4} \frac{d \xi_{i}}{d x}\right) \phi_{j}+\tilde{e}_{31}\left(\sum_{j=1}^{2} \frac{d \varsigma_{j}}{d z} \sum_{i=1}^{4} \frac{d \xi_{i}}{d x}\right) \varphi_{j}\right] \delta u_{i}\right.} \\
& {\left[k_{s} \tilde{Q}_{55}\left(\sum_{j=1}^{3} \frac{d \zeta_{j}}{d x} \sum_{i=1}^{3} \frac{d \zeta_{i}}{d x}\right) w_{j}-k_{s} \tilde{Q}_{55}\left(\sum_{j=1}^{2} \psi_{j} \sum_{i=1}^{3} \frac{d \zeta_{i}}{d x}\right) \phi_{j}+\tilde{e}_{31}\left(\sum_{j=1}^{2} \frac{d \zeta_{j}}{d z} \sum_{i=1}^{3} \frac{d \zeta_{i}}{d x}\right) \varphi_{j}\right] \delta w_{i}}
\end{aligned}
$$

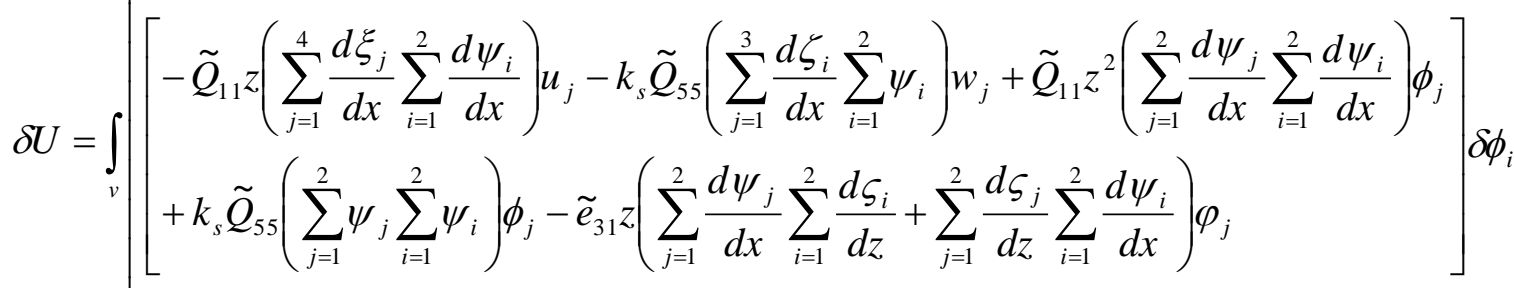

$$
\begin{aligned}
& {\left[\tilde{e}_{31}\left(\sum_{j=1}^{4} \frac{d \xi_{j}}{d x} \sum_{i=1}^{2} \frac{d \varsigma_{j}}{d z}\right) u_{j}+\tilde{e}_{31}\left(\sum_{j=1}^{3} \frac{d \zeta_{j}}{d x} \sum_{i=1}^{2} \frac{d \varsigma_{i}}{d z}\right) w_{j}-\tilde{e}_{31}\left(\sum_{j=1}^{2} \frac{d \varsigma_{j}}{d z} \sum_{i=1}^{2} \psi_{i}\right) \varphi_{j}\right.} \\
& {\left[-\tilde{e}_{31}\left(\sum_{j=1}^{2} \psi_{j} \sum_{i=1}^{2} \frac{d \varsigma_{i}}{d z}\right) \phi_{j}-\tilde{\varepsilon}_{33}^{s}\left(\sum_{j=1}^{2} \frac{d \varsigma_{j}}{d z} \sum_{i=1}^{2} \frac{d \varsigma_{i}}{d z}\right) \varphi_{j}\right.}
\end{aligned}
$$


In Eqn. (37), perform the integration through the thickness, the stiffness matrix elements are represented by:

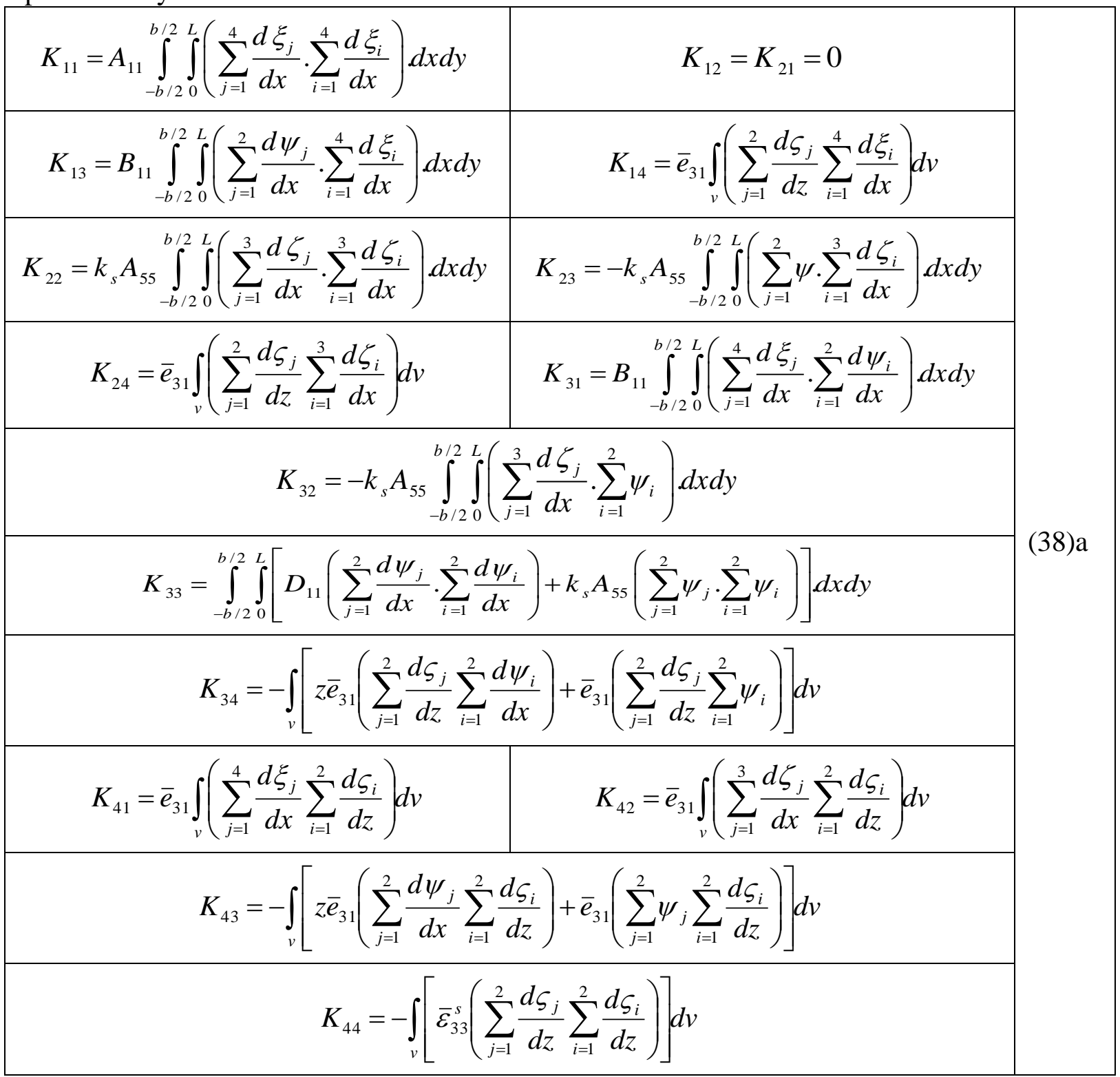

For isotropic beam, the constants $\widetilde{Q}_{11}=E$, and $\widetilde{Q}_{55}=G$. The laminate stiffness matrix elements are:

$$
\begin{array}{ll}
A_{11}=\sum_{k=1}^{N}\left(\tilde{Q}_{11}\right)_{k}\left(z_{k}-z_{k-1}\right) & A_{55}=\sum_{k=1}^{N}\left(_{\tilde{Q}_{55}}\right)_{k}\left(z_{k}-z_{k-1}\right) \\
B_{11}=\frac{1}{2} \sum_{k=1}^{N}\left(\tilde{Q}_{11}\right) \underset{k}{\left(z_{k}^{2}-z_{k-1}^{2}\right)} & D_{11}=\frac{1}{3} \sum_{k=1}^{N}\left(\tilde{Q}_{11}\right)\left(z_{k}^{3}-z_{k-1}^{3}\right)_{k} .
\end{array}
$$

The first variation of the external work, Eqn (20), is expressed as:

$$
\delta W=\iint_{R}\left[t\left(\delta u_{0}-z \delta \phi_{x}\right)+\left(f_{t} \delta w_{0}\right)-\sigma \delta \varphi\right] d x d y+\iint_{R}\left[f_{a} \delta u_{0}\right] d y d z
$$

By substituting Eqns. (22), (24), (26), and (28) into Eqn. (39), one can obtain: 


$$
\delta W=\iint_{R}\left[\xi_{j}\right] \delta u_{i} d x d y-\iint_{R} z\left[\psi_{j}\right] \delta \phi \phi_{x} d x d y+\iint_{R}\left[\zeta_{j}\right] f_{t} \delta w_{i} d x d y+\iint_{R}\left[\xi_{j}\right] f_{a} \delta u_{i} d y d z-\iint_{R}\left[\varsigma_{j}\right] \delta \delta \varphi_{i} d x d y
$$

Thus, the elements of the load vector are:

$$
\begin{aligned}
& F_{11}=\int_{-b / 2}^{b / 2} \int_{0}^{L}\left[t \xi_{1}\right] d x d y+\int_{-h / 2}^{h / 2} \int_{-b / 2}^{b / 2}\left[f_{a} \xi_{1}\right] d y d z \quad F_{12}=\int_{-b / 2}^{b / 2} \int_{0}^{L}\left[t \xi_{2}\right] d x d y+\int_{-h / 2}^{h / 2} \int_{-b / 2}^{b / 2}\left[f_{a} \xi_{2}\right] d y d z \\
& F_{13}=\int_{-b / 2}^{b / 2} \int_{0}^{L}\left[t \xi_{3}\right] d x d y+\int_{-h / 2}^{h / 2} \int_{-b / 2}^{b / 2}\left[f_{a} \xi_{3}\right] d y d z \quad F_{14}=\int_{-b / 2}^{b / 2} \int_{0}^{L}\left[t \xi_{4}\right] d x d y+\int_{-h / 2}^{h / 2} \int_{-b / 2}^{b / 2}\left[f_{a} \xi_{4}\right] d y d z \\
& F_{21}=\int_{-b / 2}^{b / 2} \int_{0}^{L}\left[f_{t} \zeta_{1}\right] d x d y \quad \int_{-b / 2}^{b / 2} \int_{0}^{L}\left[f_{t} \zeta_{2}\right] d x d y \quad F_{23}=\int_{-b / 2}^{b / 2} \int_{0}^{L}\left[f_{t} \zeta_{3}\right] d x d y \\
& F_{31}=\int_{-b / 2}^{b / 2} \int_{0}^{L}\left[t z \psi_{1}\right] d x d y \\
& F_{41}=-\int_{-b / 2}^{b / 2} \int_{0}^{L}\left[\varsigma_{1} \sigma\right] d x d y \\
& F_{32}=\int_{-b / 2}^{b / 2} \int_{0}^{L}\left[t z \psi_{2}\right] d x d y \\
& F_{42}=-\int_{-b / 2}^{b / 2} \int_{0}^{L}\left[\varsigma_{2} \sigma\right] d x d y
\end{aligned}
$$

The first variation of the kinetic energy is expressed as:

$$
\begin{aligned}
& \delta T=\int_{t_{1}}^{t_{2}}\left[\delta\left(\frac{1}{2} \int_{v} \rho\left(\dot{u}^{2}+\dot{w}^{2}\right) d v\right)\right] d t \\
& \delta T=\int_{t_{1}}^{t_{2}}\left[\int_{v} \rho(\dot{u} \delta \dot{u}+\dot{w} \delta \dot{w}) d v\right] d t
\end{aligned}
$$

By integration by parts with respect to time, note that the time $t_{1}$ and $t_{2}$ are arbitrary, except that at $t=t_{1}$, and $t=t_{2}$, all variations are zero.

$$
\delta T=-\int_{v} \rho(\ddot{u} \delta u+\ddot{w} \delta w) d v
$$

By substituting the shape functions Eqns. (22-27) in Eqn. (43), the mass matrix elements are expressed as follows:

$$
\begin{array}{lll}
M_{11}=I_{0} \int_{0}^{L}\left[\xi_{i}\right]^{T}\left[\xi_{i}\right] d x & \mathrm{i}=1, . ., 4 & M_{12}=0 \\
M_{13}=-I_{1} \int_{0}^{L}\left[\xi_{i}\right]^{T}\left[\psi_{j}\right] d x & \mathrm{i}=1, . ., 4, \text { and } \mathrm{j}=1,2 & \\
M_{21}=0 & M_{22}=I_{0} \int_{0}^{L}\left[\zeta_{i}\right]^{T}\left[\zeta_{i}\right] d x \quad \mathrm{i}=1, . ., 3 & M_{23}=0 \\
M_{31}=-I_{1} \int_{0}^{L}\left[\psi_{i}\right]^{T}\left[\xi_{j}\right] d x & \mathrm{i}=1,2, \text { and } \mathrm{j}=1, . ., 4 & M_{32}=0 \\
M_{33}=I_{2} \int_{0}^{L}\left[\psi_{i}\right]^{T}\left[\psi_{i}\right] d x & \mathrm{i}=1,2 \quad \text { and } \quad\left(I_{0}, I_{1}, I_{2}\right)=\rho \int_{A}\left(1, z, z^{2}\right) d A
\end{array}
$$

where $I$ is the moment of inertia and $\rho$ is the mass density of the material. 
Substituting by the shape function equations (23), (25), (27) and (30) into Equations (38)a, Eqn. (41) and Eqn.(44), and perform the integration for a beam element with length L, width $b$ and height $h$, The elements of stiffness matrix, load vector, and mass matrix are obtained and given in Appendix B.

\section{Equation of Motion}

The equation of motion of the whole structure system is represented by:

$$
\left[\begin{array}{cc}
M_{q q} & 0 \\
0 & 0
\end{array}\right]\left\{\begin{array}{l}
\ddot{U} \\
\ddot{\varphi}
\end{array}\right\}+\left[\begin{array}{cc}
K_{q q} & K_{q \varphi} \\
K_{\varphi q} & K_{\varphi \varphi}
\end{array}\right]\left\{\begin{array}{l}
U \\
\varphi
\end{array}\right\}=\left\{\begin{array}{l}
F \\
G
\end{array}\right\}
$$

where $M_{u u}$ is the global mass matrix of the structure and $\{U\}$ is the global nodal generalized displacements coordinates vector, $\{\varphi\}$ is the global nodal generalized electric coordinates vector describing the applied voltages at the actuators [23], $\{F\}$ is the applied mechanical load vector, and $\{G\}$ is the electric excitation vector.

The proposed finite element model is presented and tested for verification in Ref. [31] for the analysis of solid Timoshenko beams only. For the present study, a MATLAB code is constructed to perform the finite element analysis of isotropic and anisotropic smart beams with piezoelectric materials using Timoshenko beam theory. The static and free vibration analyses are preformed for beams subjected to different kinds of mechanical and electrical loads. The inputs to the code are the geometric properties of the structure such as the dimensions, the moment of inertia of beam, the adhesive layer, the piezoelectric patch, number of layers, ply orientations angle, and the material properties of the structure system units. The present model is capable of predicting the nodal (axial and transversal) deformation, and the fundamental natural frequency of the beam.

\section{Validation Examples}

In the following, the behavior of a laminated aluminum beam and a graphite epoxy composite beam with a piezoelectric actuator are investigated using the interactive MATLAB code. The geometry of the smart beam, structure substrate, earth connection, adhesive layer, and piezoelectric layer (PZT- 4) are shown in Figure 3. The properties of both isotropic and anisotropic beams are listed in Table 1 [9].
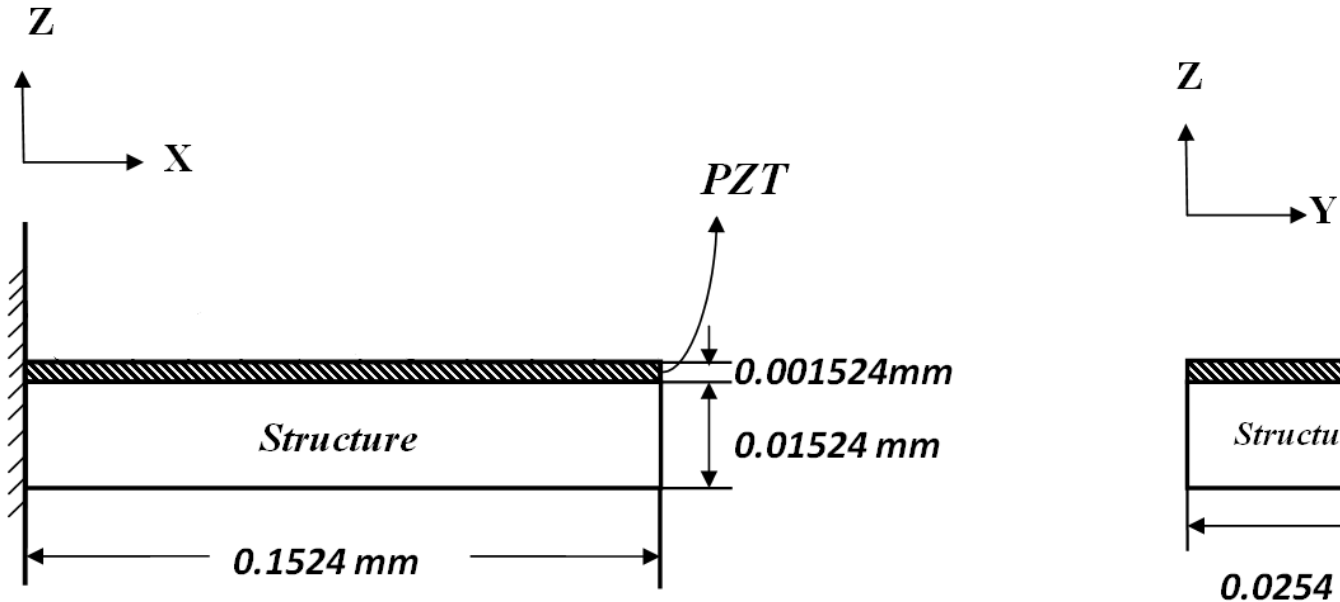

Figure (3): Smart Beam with PZT layer. 


\section{Convergence of the Proposed Model Results}

The convergence of the predicted results of the MATLAB code is checked for both isotropic and anisotropic smart beams, respectively. The code is fed with the data listed in Table 1 for each type of smart beams. Figure 4 plots the predicted change of transverse deflection with the number of elements for the isotropic smart beam, whereas Figure 5 plots the same behavior for anisotropic smart beam. For each smart beam, it is seen from its respective figure that the trend of the predicted transverse deflection decreases with increasing the number of elements until it finally reaches a constant asymptotic value at certain numbers of elements. The obtained result proves the convergence of the predicted results of the present finite element model.

Table (1): Material properties of aluminum beam, T300/934 Graphite/ epoxy [0] composite Beam, and piezoelectric actuator [9].

\begin{tabular}{|l|c|c|c|c|}
\hline \multicolumn{1}{|c|}{ Properties } & $\begin{array}{c}\text { Aluminum } \\
\text { beam }\end{array}$ & $\begin{array}{c}\text { T300/934 Graphite/ epoxy } \\
\text { [0] composite beam }\end{array}$ & $\begin{array}{c}\text { Adhesive } \\
\text { layer }\end{array}$ & $\begin{array}{c}\text { PZT-4 } \\
\text { actuator }\end{array}$ \\
\hline$E_{11}(\mathrm{GPa})$ & 68.9 & 126 & 6.9 & 83 \\
\hline$E_{33}(\mathrm{GPa})$ & 68.9 & 7.9 & 6.9 & 66 \\
\hline$\gamma_{13}$ & 0.25 & 0.275 & 0.4 & 0.31 \\
\hline$G_{13}(\mathrm{GPa})$ & 27.6 & 3.4 & 2.46 & 31 \\
\hline$d_{31}(\mathrm{~m} / \mathrm{v})$ & 0 & 0 & 0 & $-122 \times 10^{-12}$ \\
\hline$d_{33}(\mathrm{~m} / \mathrm{v})$ & 0 & 0 & 0 & $285 \times 10^{-12}$ \\
\hline$\varepsilon_{33}^{s}(\mathrm{~F} / \mathrm{m})$ & 0 & 0 & 0 & $11.53 * 10^{-9}$ \\
\hline$\rho\left(k g / m^{3}\right)$ & 2769 & 2527 & 1662 & 7600 \\
\hline Length $(m)$ & 0.1524 & 0.1524 & 0.1524 & 0.1524 \\
\hline Thickness $(m)$ & 0.01524 & 0.01524 & 0.000254 & 0.001524 \\
\hline Width $(m)$ & 0.0254 & 0.0254 & 0.0254 & 0.0254 \\
\hline
\end{tabular}

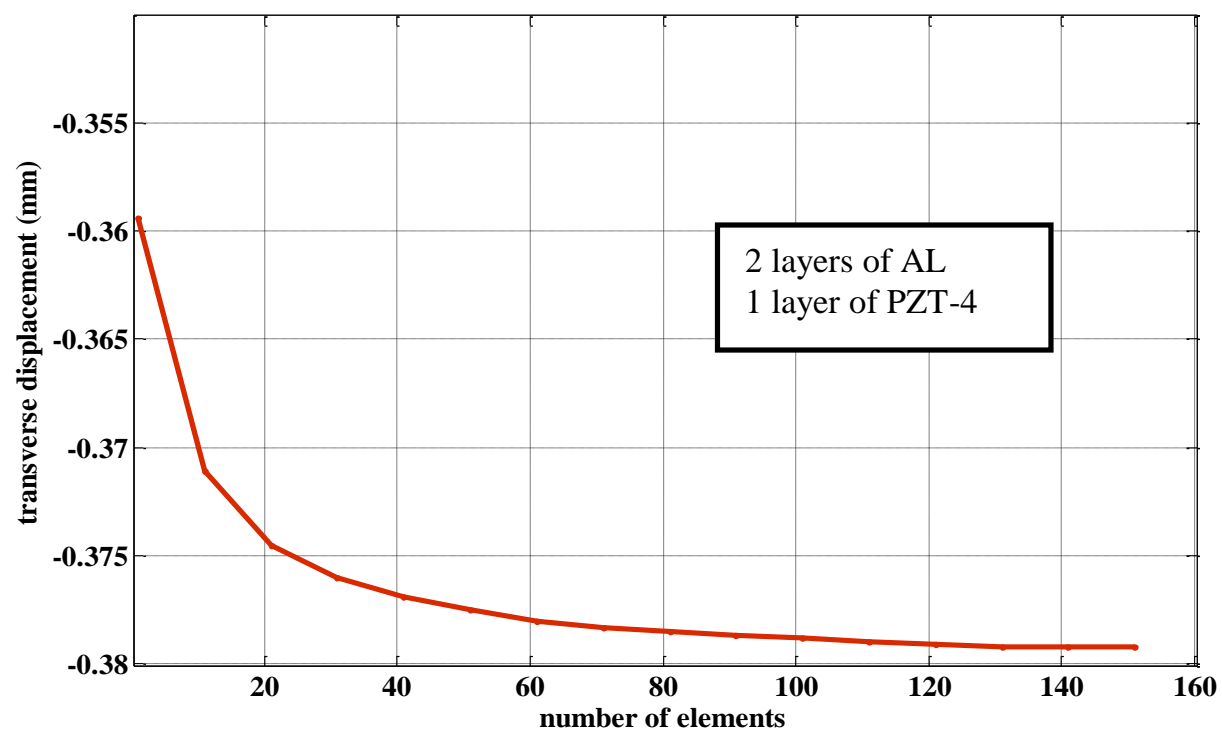

Figure (4): The predicted change of transverse deflection with number of elements for smart isotropic beam. 


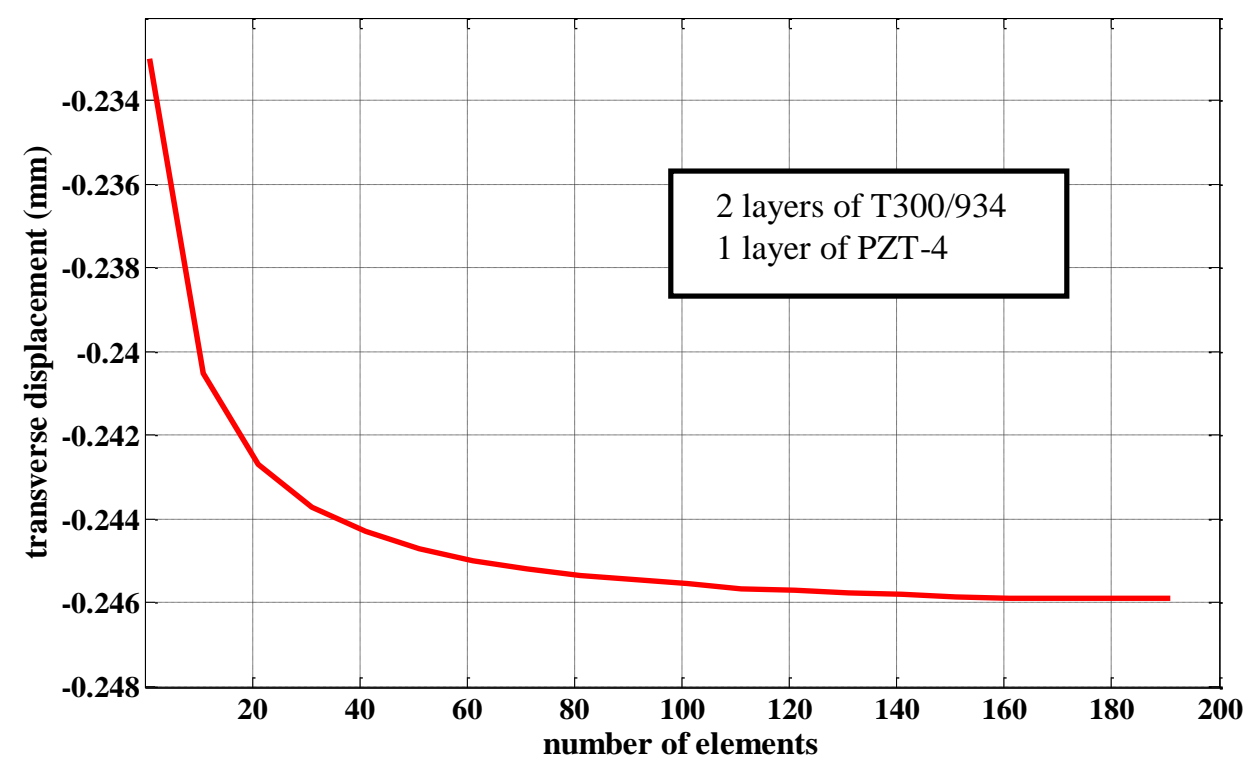

Figure (5): The predicted change of transverse deflection with number of elements for smart anisotropic beam.

\section{Smart Beam Results}

\section{Static analysis}

Each of isotropic or anisotropic smart beams with its respective data listed in Table 1 is subjected to a constant electric potential of $12.5 \mathrm{kV}$. The electric load was applied on the upper surface of the PZT-4 layer, while the lower surface was grounded $(0 \mathrm{~V})$ [14]. The proposed model predicts the transverse deflections of the isotropic and anisotropic smart beams, respectively, using number of elements of twenty, the parameter $\left(e_{31}=c_{11} d_{31}\right)$, and shear correction factor $k_{s}$ of 5/6. Figure 6 plots the predicted transverse deflections obtained by the present model for the isotropic beam (AL-PZT), whereas Figure 7 plots the predicted transverse deflections for the anisotropic beam (Graphite/epoxy [0] composite T300/940-PZT). The corresponding predictions obtained by Refs. [8-9-14] for each smart beam are plotted on their respective figure. Good agreement is generally obtained between the obtained results by the present model and that of Refs. [8-9-14].

The response of both cantilever beams of aluminum and T300/934 Graphite/epoxy [0/90/0/...] composite beams operating in a sensory mode with a transverse load of $1000 \mathrm{~N}$ upwards at the free end of the beam is investigated. The lower surface of the piezoelectric layer is grounded $(0$ volt) and the signal is acquired from the electrode on the top surface. The Effect of number of layers of the beams on the transverse deflection is shown in Figure (8) and they compare with the results obtained by Ref. [14]. It is seen from the figure that as the number of layers increases, the beam stiffness increases, and the non-dimensional transverse deflection decreases.

Figures (9) and (10) present the effect of the applied voltages on the transverse displacements of aluminum beam and T300/934 Graphite/epoxy [0] composite beam with PZT-4 actuator, respectively. For each smart beam, the corresponding predicted effect using the proposed model of Ref. [14] is plotted on its respective figure. It is seen from both figures that the transverse displacement increases with the increase of applied voltage. In addition, the obtained results of the proposed model are matched with that predicted by Ref. [14]. 


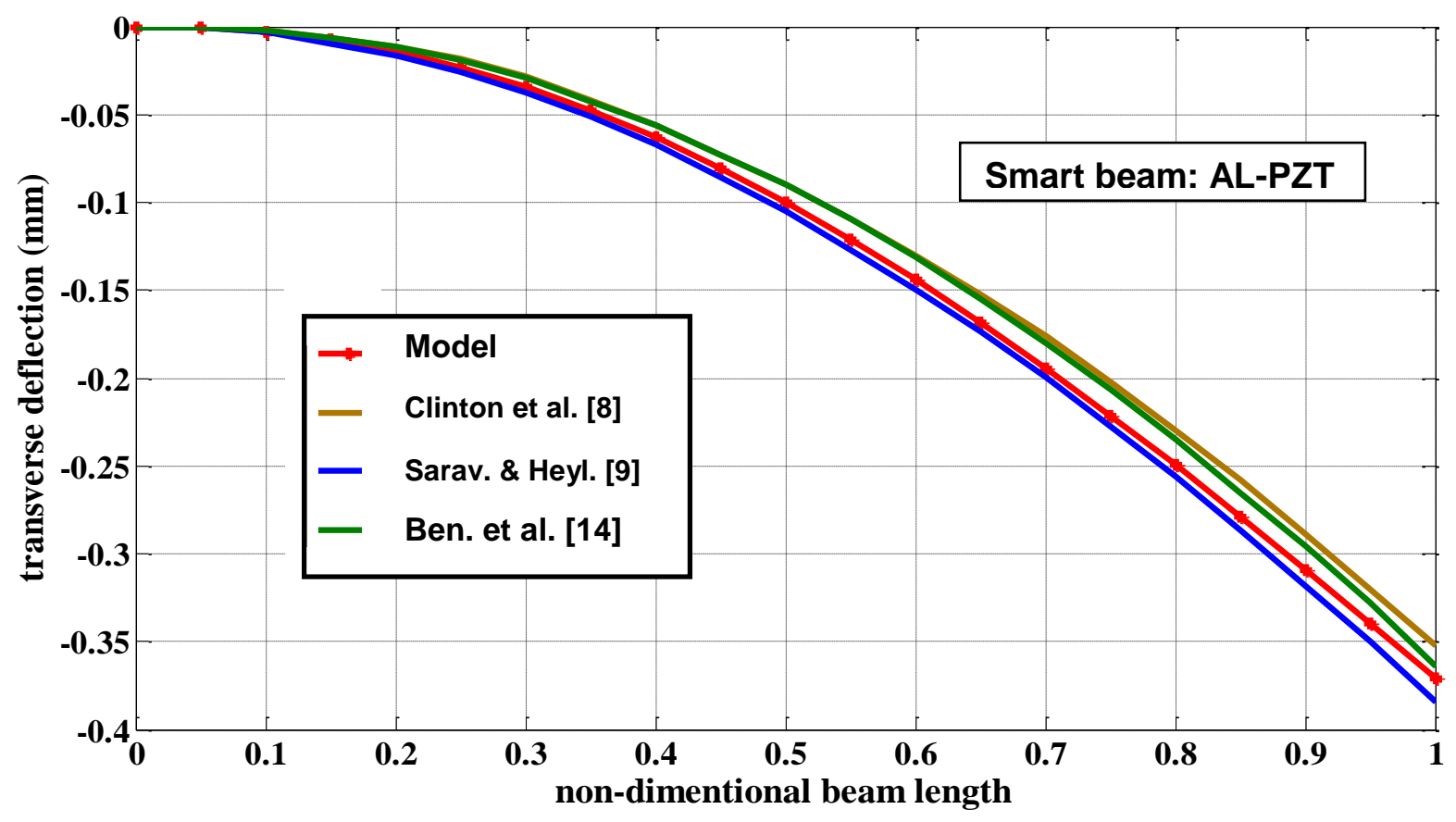

Figure (6): Comparison between the transverse deflections obtained by the proposed model and that of Refs.[8-9-14] for aluminum beam with PZT.

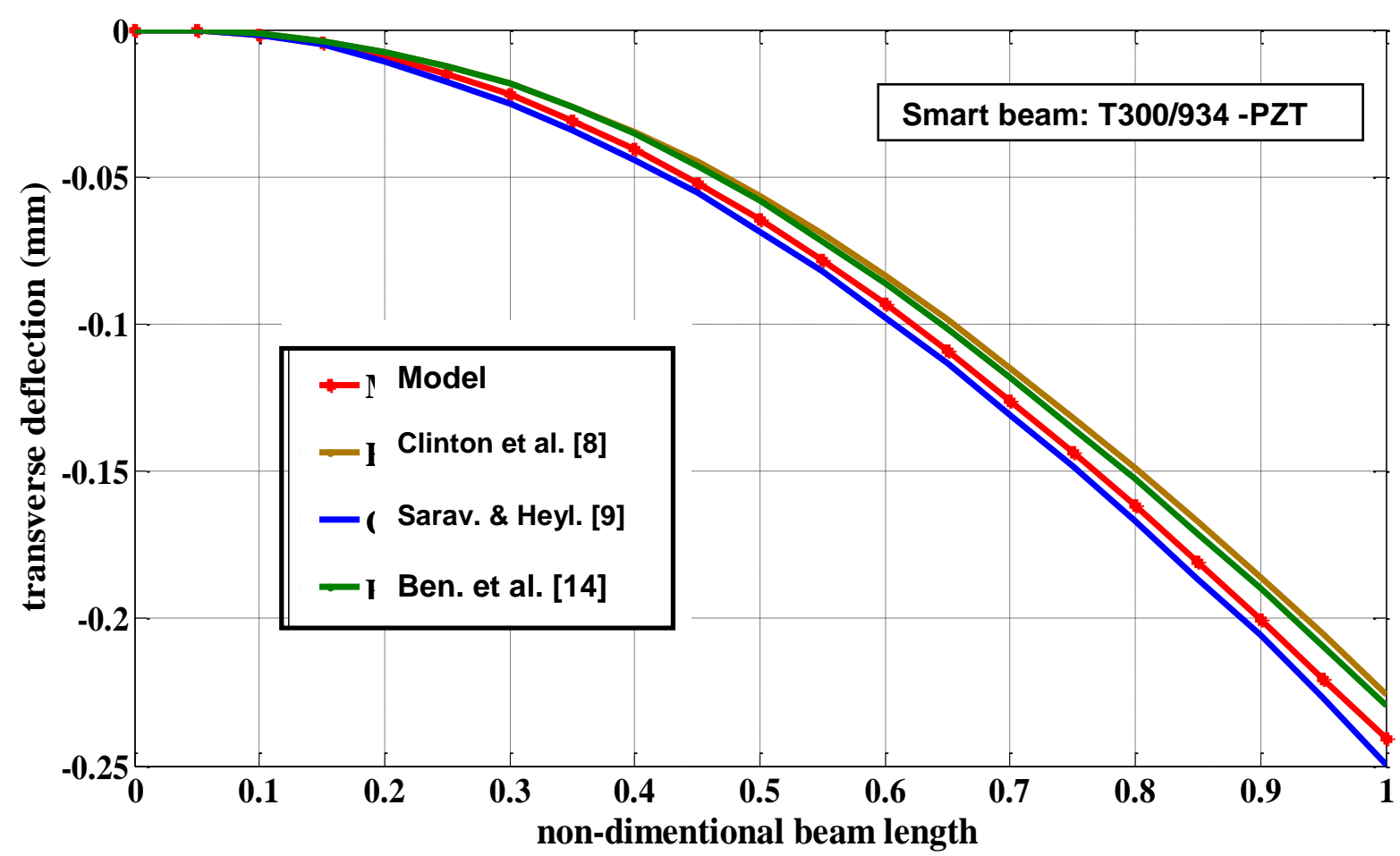

Figure (7): Comparison between the transverse deflections obtained by the proposed model and that of Refs.[8-9-14] for T300/934 Gr./epoxy [0] composite beam with PZT. 


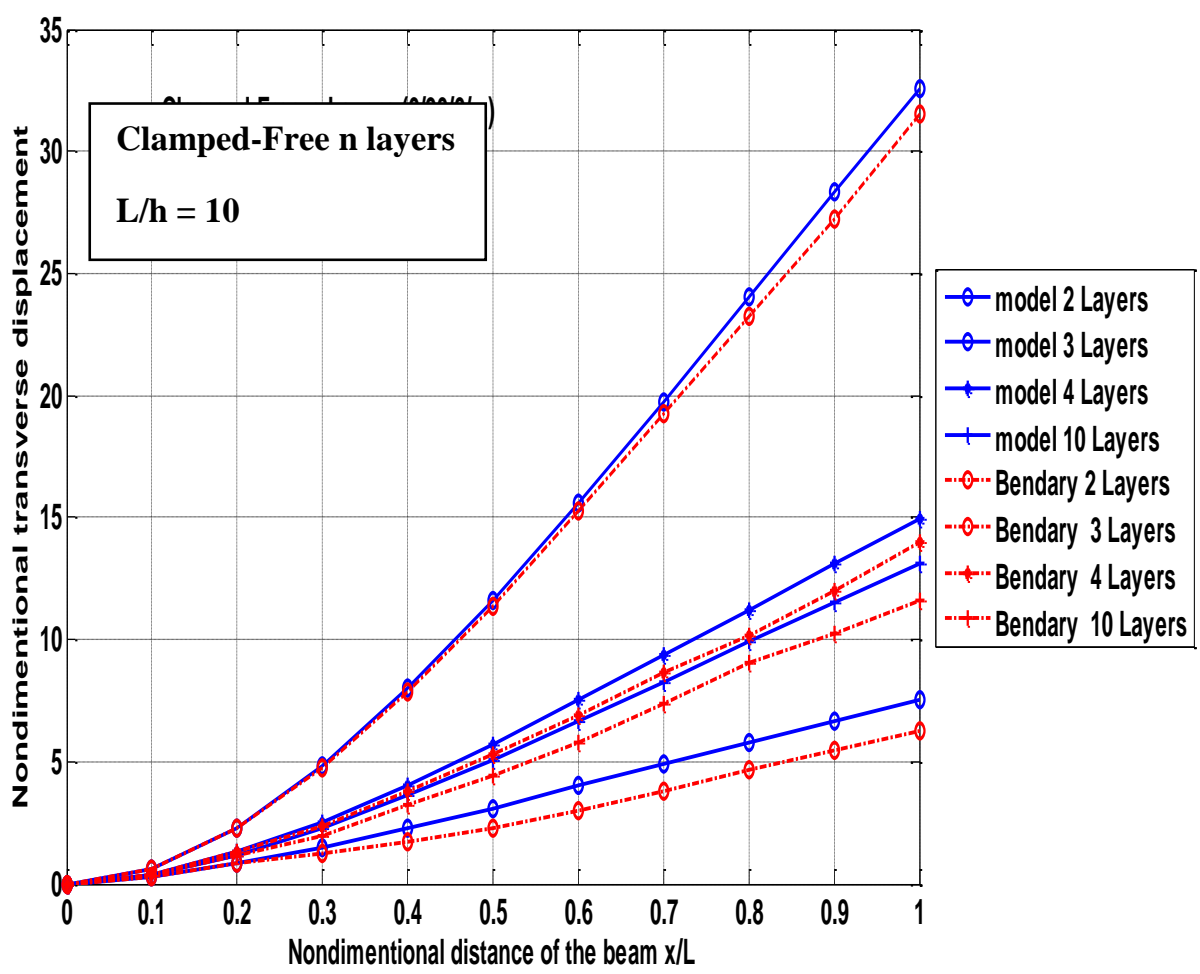

Figure (8): Non-dimensional transverse deflection vs. non-dimensional distance along the beam lenght $\mathrm{x} / \mathrm{L}$.

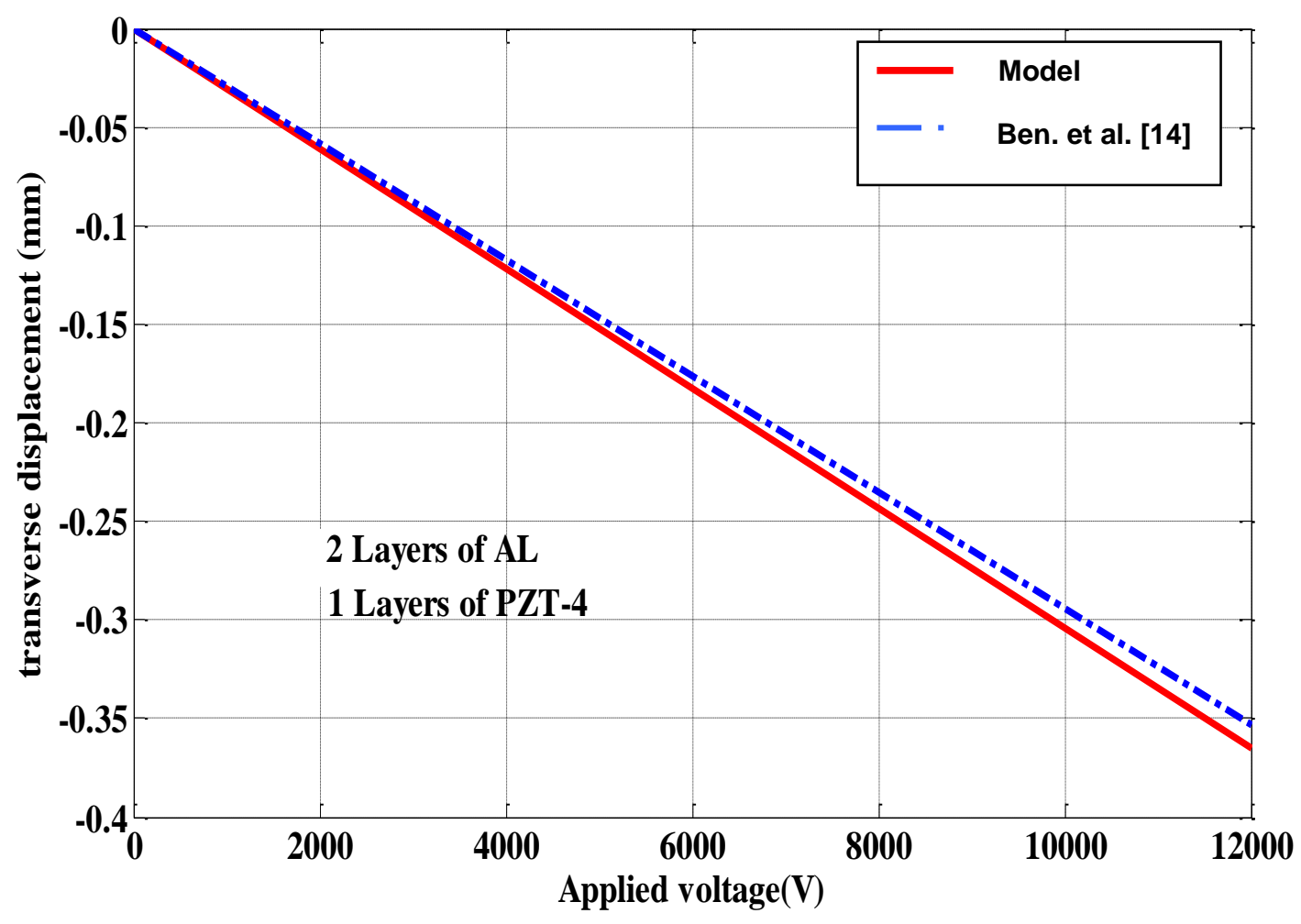

Figure (9): Transverse displacement vs. applied voltage for aluminum beam with piezoelectric actuator. 


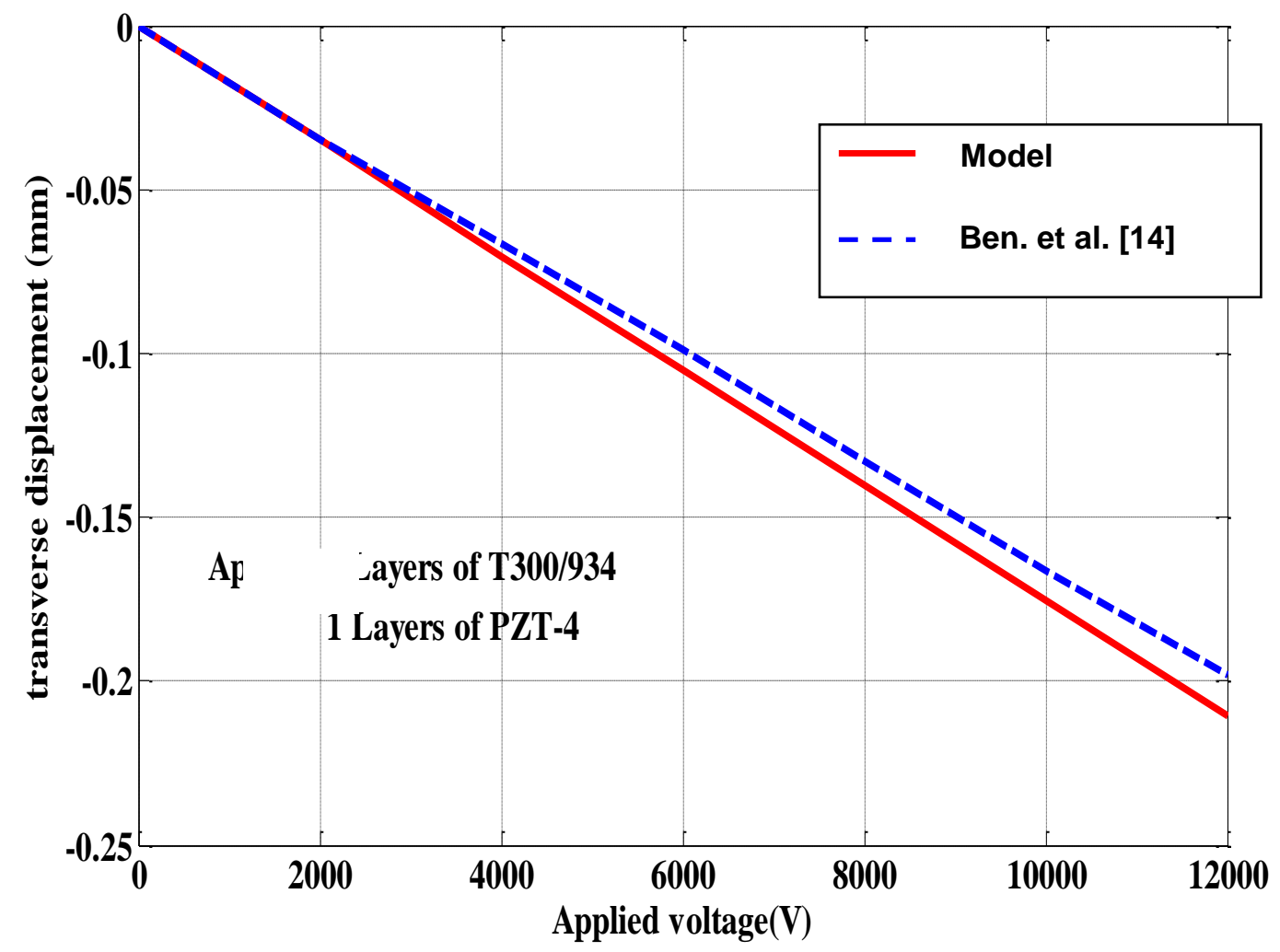

Figure (10): Transverse displacement vs. applied voltage for T300/934 Graphite/epoxy [0] composite beam with piezoelectric actuator.

Figures (11) and (12) show the effect of applied voltage on the axial displacements of aluminum beam and T300/934 Graphite/epoxy [0] composite beam with PZT-4 actuator. For each smart beam, the corresponding predicted results by the model of Ref. [14] are plotted on its respective figure. It is seen from both figures that the axial displacement increases almost linearly with increasing the applied voltages. In addition, the increased value of axial displacement is found to be an order of magnitude smaller than the increased value of the transverse displacement.

\section{Dynamic Analysis}

Table 2 lists the free dynamic predictions of the fundamental natural frequencies of the aluminum beam when the applied voltage on the upper surface of the PZT-4 is equal to zero. The natural frequencies predicted by the present model are compared with that of Refs. [9-1014]; excellent agreement is obtained by the present model using number of elements of twenty.

Table (2): Predicted natural frequencies of aluminum beam with single PZT- 4 layer.

\begin{tabular}{|l|l|l|l|l|}
\hline \multirow{2}{*}{$\begin{array}{l}\text { No. of } \\
\text { elements }\end{array}$} & \multicolumn{4}{|l|}{ Natural frequencies obtained by } \\
\cline { 2 - 5 } & Ref. [9] & Ref. [10] & Ref. [14] & $\begin{array}{l}\text { Present } \\
\text { Model }\end{array}$ \\
\hline 10 & 539.3 & 539.7 & 530.9 & 540.5 \\
\hline 20 & 538.6 & 539.3 & 530.9 & 539.3 \\
\hline 30 & 538.5 & 539.1 & 530.8 & 539.1 \\
\hline
\end{tabular}




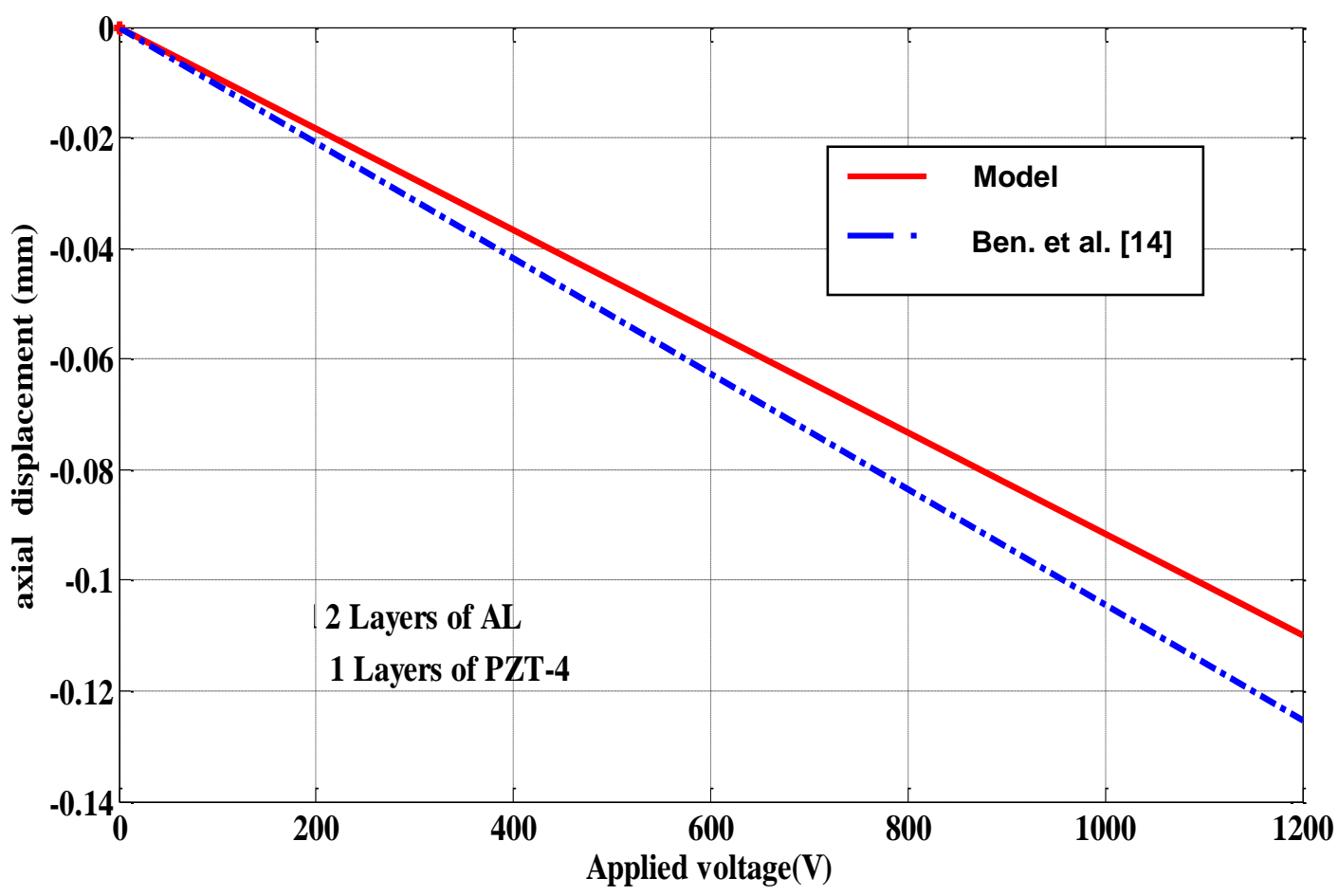

Figure (11): Axial displacement vs. applied voltage for aluminum beam with piezoelectric actuator.

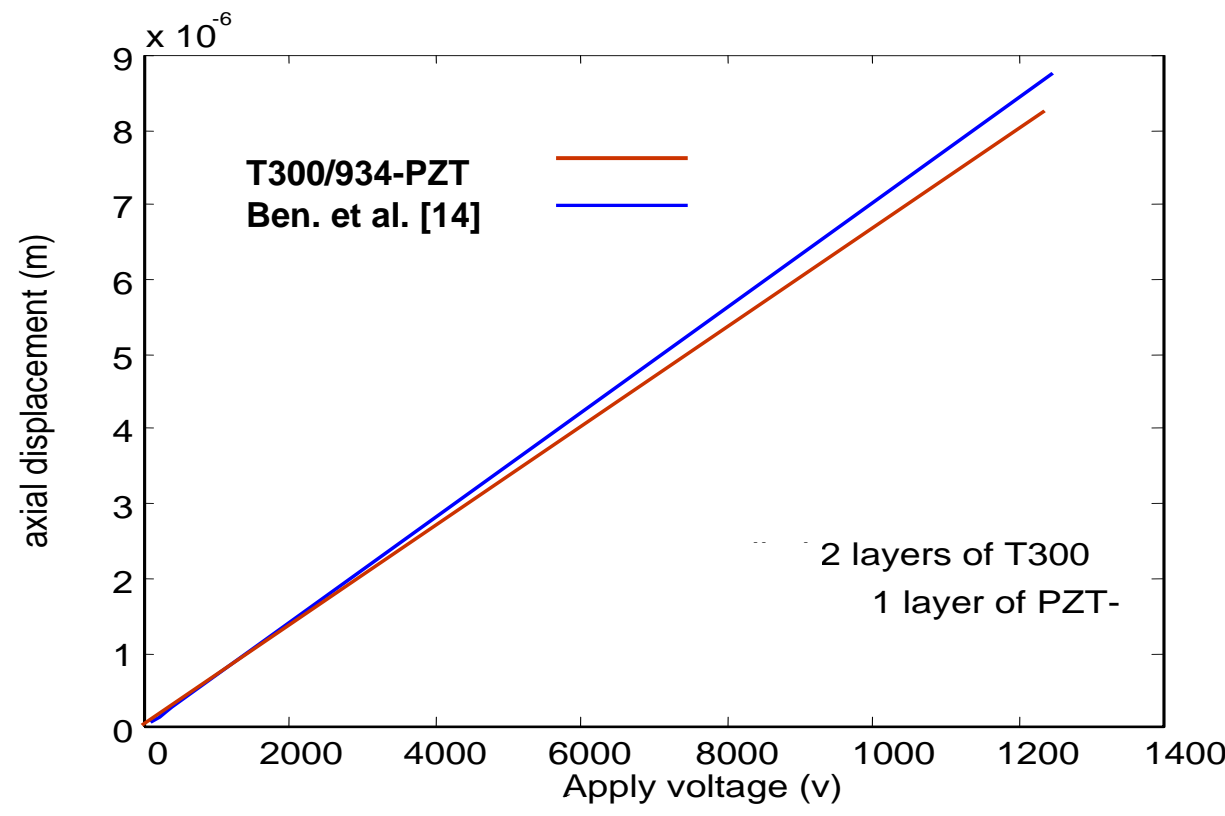

Figure (12): Axial displacement vs. applied voltage for T300/934 Graphite/epoxy [0] composite beam with piezoelectric actuator.

The obtained results of the proposed finite element model prove its validity and predictive capabilities in comparison with the results of some models proposed by other investigators as follows:

1. The proposed model is based on Timoshenko beam theory which does not need more computational effort as the layer wise method that used for constructing the model proposed 
by Saravanos and Heyliger due to the greater degrees of freedom used [9]. In addition, the present model has the following advantages:

- It represents the strong heterogeneity in composite laminate with piezoelectric layer model

- It is capable of capturing the effects induced from the discontinuous variation of properties and anisotropy through-the-thickness of the laminate.

- It is suitable for predicting the response of moderate laminate thicknesses and smart structure system which entails additional heterogeneity from the piezoelectric layer and induced strain actuation [9].

- The use of the shear correction factor improved the present model prediction.

2. The present model has better predictions compared to the model proposed by Bend. et al. [14] in which the CBT theory is used for constructing such model without including the shear effect.

3. The predictions of the present model have lower accuracy than the predictions of the model proposed by Clinton et al. [8] for the following:

- The mathematical model of Ref. [8] was based on a high order displacement field coupled with a layer wise linear electric potential. However, the predictions of the present Timoshenko model with suitable number of elements not only give close results to that predicted by the model of Ref. [8], but also it does not need a computational effort as this reference done.

- The present model allows any element to be non-active or active (an actuator or a sensor), like the model of Ref. [8] highlighted.

\section{Conclusions}

A finite element model has been proposed to predict the static and the free dynamic characteristics of laminated aluminum and fiber reinforced composite beams with piezoelectric materials using Timoshenko beam theory. The following conclusions have been drawn:

1. The good agreement between the present model predictions using Timoshenko beam theory, and the corresponding predicted results of other investigators using a layer wise theory with different models and HODT modeling, proves the predictive capabilities of such model with less computational effort.

2. The present model predictions using Timoshenko beam theory was better than the results obtained by a simple Euler-Bernoulli's beam theory but it required more computational effort due to inclusion of the transverse shear effects.

3. The validity of representing the electric potential function in the proposed finite element model of the Timoshenko beam.

4. The proposed finite element model results were obtained at resizable number of elements

5. As the applied voltage increases, both the transverse and axial displacements increase, respectively.

6. As the number of layers increases, the transverse deflection decreases.

7. The inclusion of shear correction factor in the present model improved its predictions.

8. The model can be extended to the following:

- Using the simple higher order shear deformation theory made by Reedy, to improve the predictions of the transverse shear effects.

- Taking into account the geometric nonlinearities in the finite element model which may improve the obtained results. 


\section{References}

\begin{tabular}{|c|c|}
\hline [1] & $\begin{array}{l}\text { A.A. Khdeir, and J.N. Reddy, "An Exact Solution for the Bending of Thin and Thick } \\
\text { Cross-Ply Laminated Beams", Computers \& Structures, Vol. 37, 1997, pp.195-203. }\end{array}$ \\
\hline [2] & $\begin{array}{l}\text { V. Yildirm, E. Sancaktar and E. Kiral, "Comparison of the In-Plan Natural Frequencies } \\
\text { of Symmetric Cross-Ply Laminated Beams Based On The Bernoulli-Eurler and } \\
\text { Timoshenko Beam Theories", J. of Appl. Mech., Vol. 66, 1999, pp. 410-417. }\end{array}$ \\
\hline [3] & $\begin{array}{l}\text { S.M. Nabi and N. Ganesan, "Generalized Element for the Free Vibration Analysis of } \\
\text { Composite Beams", Computers \& Structures, Vol. 51, No. 5, 1994, pp. 607-610. }\end{array}$ \\
\hline [4] & $\begin{array}{l}\text { K. Chandrashekhara and K.M. Bangera, "Free Vibration of Composite Beams Using a } \\
\text { Refined Shear Flexible Beam Element" Computers and Structures, Vol. 43, No.4, } \\
\text { 1992, pp.719-727. }\end{array}$ \\
\hline [5] & $\begin{array}{l}\text { A. Henno and T.J.R. Huges, "Finite Element Method for Piezoelectric Vibration", Int. } \\
\text { J. for Numerical Methods in Engineering", Vol. 2, 1970, pp. 151-157. }\end{array}$ \\
\hline [6] & $\begin{array}{l}\text { E.F. Crawley and K.B. Lazarus, "Induced Strain Actuation of Isotropic and Anisotropic } \\
\text { Plates", AIAA J., Vol. 29, No. 6, 1991, pp. 944-951. }\end{array}$ \\
\hline [7] & $\begin{array}{l}\text { K.K. Ang, J.N. Reddy and C.M. Wang, "Displacement Control of Timoshenko Beams } \\
\text { via Induced Strain Actuators", Smart Materials and Structures, Vol. 9, 2000, pp. 981- } \\
\text { 984. }\end{array}$ \\
\hline [8] & $\begin{array}{l}\text { Y.K. Clinton Chee, L. Tong and P.S. Grant, "A mixed Model for Composite Beams } \\
\text { with Piezoelectric Actuators And Sensors", Smart Materials and Structures, Vol. 8, } \\
\text { 1999, pp. 417-432. }\end{array}$ \\
\hline [9] & $\begin{array}{l}\text { D.A. Saravanos and P.R. Heyliger, "Coupled Layerwise Analysis of Composite Beams } \\
\text { with Embedded Piezoelectric Sensors and Actuators", J. of Intelligent Material } \\
\text { Systems and Structures, Vol. 6, 1995, pp. 350-363. }\end{array}$ \\
\hline [10] & $\begin{array}{l}\text { D.H. Robbins and J.N. Reddy, "Analysis of Piezoelectrically Actuated Beams Using A } \\
\text { Layer-Wise Displacement Theory", Computers \& Structures, Vol. 41, No.2, 1991, pp. } \\
\text { 265-279. }\end{array}$ \\
\hline [11] & $\begin{array}{l}\text { Q. Wang and S.T. Quek, "Dispersion Relations In Piezoelectric Coupled Beams"," } \\
\text { AIAA J., Vol. 38, No. 12, 1996, pp. 2357-2361. }\end{array}$ \\
\hline [12] & $\begin{array}{l}\text { ZHOU Yan-guo; CHEN Yun-min; and DING Hao-jiang, "Analytical Modeling and } \\
\text { Free Vibration Analysis of Piezoelectric Bimorphs", Journal of Zhejiang University } \\
\text { Science, } 2005 \text { 6A(9): 938-944. Received Mar. 1, 2005; Revision accepted Apr. 20, } \\
2005 .\end{array}$ \\
\hline [13] & $\begin{array}{l}\text { C.W.H. Lau, C.W. Lim and A.Y.T. Leung, "A Variational Energy Approach for } \\
\text { Electromechanical Analysis of Thick Piezoelectric Beam", Journal of Zhejiang } \\
\text { University Science, 2005 6A (9): pp. 962-966. }\end{array}$ \\
\hline [14] & $\begin{array}{l}\text { I.M. Bendary, M.A. Elshafei and A.M. Riad, " Finite Element Model of Smart Beams } \\
\text { with Distributed Piezoelectric Actuators ", J. of Intelligent Material Systems and } \\
\text { Structures, Vol. 21, 2010, pp. 747-758. }\end{array}$ \\
\hline [15] & $\begin{array}{l}\text { J.N. Reddy, "Mechanics of Laminated Composite Plates and Shells, Theory and } \\
\text { Analysis", 2nd edition, CRC Press, USA, } 2004 .\end{array}$ \\
\hline [16] & $\begin{array}{l}\text { J.N. Reddy, "An Introduction to Nonlinear Finite Element Analysis ",Oxford } \\
\text { University Press, USA (2004). }\end{array}$ \\
\hline [17] & $\begin{array}{l}\text { Gibson R.F., "Principles of composite material mechanics", McGraw-Hill Inc., , } \\
\text { Printed in the USA, 1994, pp.201-207. }\end{array}$ \\
\hline [18] & $\begin{array}{l}\text { D. Gay and S.V. Hoa, ' Composite Materials Design and Applications, 2nd edition', } \\
\text { CRC Press, USA, 2007. }\end{array}$ \\
\hline [19] & $\begin{array}{l}\text { IEEE Standard on Piezoelectricity; ' IEEE Std. 176-1978', The Institute of electrical } \\
\text { and electronics engineers, Inc., NY, USA, 1978, pp. } 12 .\end{array}$ \\
\hline
\end{tabular}




\begin{tabular}{|c|c|}
\hline [20] & $\begin{array}{l}\text { W.G. Cady, "Piezoelectricity", Dover, NY and McGraw Hill Publications, NY, USA, } \\
\text { 1964. }\end{array}$ \\
\hline [21] & $\begin{array}{l}\text { J. F. Nye, "Physical Properties of Crystals", Oxford Univ. Press. Inc. Printed in the } \\
\text { USA, 1985, pp.110-115. }\end{array}$ \\
\hline [22] & $\begin{array}{l}\text { T. Ikeda, "Fundamental of Piezoelectricity", Oxford Univ. Press Inc., Printed in the } \\
\text { USA, 1996, pp. 5-17. }\end{array}$ \\
\hline [23] & $\begin{array}{l}\text { M. Adnan Elshafei, "Smart Composite Plate Shape Control Using Piezoelectric } \\
\text { Materials"; Ph.D. Dissertation, U.S Naval postgraduate school, CA, Sep. (1996), p.17, } \\
\text { p. 53, p64, and p. 66. }\end{array}$ \\
\hline [24] & $\begin{array}{l}\text { O.J. Aldraihem and A.A. Khdeir, "Smart Beams with Extension and Thickness-Shear } \\
\text { Piezoelectric Actuators", Smart Materials and Structures, Vol. 9, 2000, pp. 1-9. }\end{array}$ \\
\hline [25] & $\begin{array}{l}\text { D.H. Allin and W.E. Hasiler, "Introduction to Aerospace Structural Analysis", John } \\
\text { Willy \& Sons, NY, USA, 1985, p. 149,154, 281, 292, and } 295 \text {. }\end{array}$ \\
\hline [26] & $\begin{array}{l}\text { A. Benjeddou, M.A. Trindade and R. Ohayon," Piezoelectric Actuation Mechanisms } \\
\text { for Intelligent Sandwich Structures", Smart Materials and Structures, Vol. 9, 2000, pp. } \\
\text { 328-335. }\end{array}$ \\
\hline [27] & $\begin{array}{l}\text { J.N. Reddy, "An introduction of the Finite Element Method", } 2^{\text {nd }} \text { edition, McGraw-Hill } \\
\text { Inc., USA, 1993, p.148. }\end{array}$ \\
\hline [28] & $\begin{array}{l}\text { O.C. Zienkiewicz and R.L. Taylor, "The Finite Element Method } 4^{\text {th }} \text { edition volume1: } \\
\text { Basic Formulation and Linear Problems", McGraw-Hill book company Europe, USA, } \\
\text { 1989, pp.230-242. }\end{array}$ \\
\hline [29] & $\begin{array}{l}\text { R.D. Cook, D.S. Malkus and M.E. Plesha, "Concept and Applications of Finite } \\
\text { Element Analysis", } 3{ }^{\text {rd }} \text { Edition, John Wiley \& sons, NY, USA, 1974, p. } 96 .\end{array}$ \\
\hline [30] & $\begin{array}{l}\text { A. Benjeddou, M.A. Trindade and R. Ohayon, "A Unified Beam Finite Element Model } \\
\text { for Extension and Shear Piezoelectric Actuation Mechanisms", J. Intelligent material } \\
\text { systems and structures, Vol. 8, No. 12, 1997, pp. 1012-1025. }\end{array}$ \\
\hline [31] & $\begin{array}{l}\text { M.A. Elshafei, M. R. Ajala and A.M. Riad, "Modeling and analysis of isotropic and } \\
\text { anisotropic Timoshenko beams using Finite Element Method", Proc. of the 14th } \\
\text { International Conf. on Applied Mechanics and Mechanical Engineering, AMME-14, } \\
\text { Military Technical College, Cairo, Egypt., May 2010. }\end{array}$ \\
\hline
\end{tabular}

\section{Appendix A}

The stress-strain relation for a thin orthotropic lamina of an anisotropic beam having coincidence of principal axis on geometric axis is given by [18]:

$$
\begin{aligned}
& \left\{\begin{array}{l}
\sigma_{1} \\
\sigma_{2} \\
\sigma_{6}
\end{array}\right\}=\left[\begin{array}{ccc}
Q_{11} & Q_{12} & 0 \\
Q_{12} & Q_{22} & 0 \\
0 & 0 & Q_{66}
\end{array}\right]\left\{\begin{array}{l}
\varepsilon_{1} \\
\varepsilon_{2} \\
\varepsilon_{6}
\end{array}\right\} \\
& \left\{\begin{array}{l}
\sigma_{4} \\
\sigma_{5}
\end{array}\right\}=\left[\begin{array}{cc}
Q_{44} & 0 \\
0 & Q_{55}
\end{array}\right]\left\{\begin{array}{l}
\varepsilon_{4} \\
\varepsilon_{5}
\end{array}\right\}
\end{aligned}
$$

where, $Q_{i j}$ is the reduced stiffness coefficient.

The components of the lamina stiffness matrix in terms of the engineering constants are given as: 


$$
\begin{aligned}
& Q_{11}=\frac{E_{1}}{1-v_{12} v_{21}}, \quad Q_{12}=\frac{v_{12} E_{2}}{1-v_{12} v_{21}}, \quad Q_{66}=G_{12} \\
& Q_{22}=\frac{E_{2}}{1-v_{12} v_{21}}, \quad Q_{44}=G_{23}, \quad Q_{55}=G_{13},
\end{aligned}
$$

where; $E_{1}$ and $E_{2}$ are the Young's modulus in the longitudinal and the transversal directions of the fiber, respectively, and $v_{12}$, and $v_{21}$ are Poisson's ratios in the two directions. The stressstrain relation of a lamina in the geometric directions $\mathrm{x}, \mathrm{y}$ and $\mathrm{z}$ is given by:

$$
\begin{aligned}
& \left\{\begin{array}{l}
\sigma_{x x} \\
\sigma_{y y} \\
\sigma_{x y}
\end{array}\right\}=\left[\begin{array}{lll}
\bar{Q}_{11} & \bar{Q}_{12} & \bar{Q}_{16} \\
\bar{Q}_{12} & \bar{Q}_{22} & \bar{Q}_{26} \\
\bar{Q}_{16} & \bar{Q}_{26} & \bar{Q}_{66}
\end{array}\right]\left\{\begin{array}{l}
\varepsilon_{x x} \\
\varepsilon_{y y} \\
\gamma_{x y}
\end{array}\right\} \\
& \left\{\begin{array}{l}
\sigma_{y z} \\
\sigma_{x z}
\end{array}\right\}=\left[\begin{array}{ll}
\bar{Q}_{44} & \bar{Q}_{45} \\
\bar{Q}_{45} & \bar{Q}_{55}
\end{array}\right]\left\{\begin{array}{l}
\gamma_{y z} \\
\gamma_{x z}
\end{array}\right\}
\end{aligned}
$$

where $\bar{Q}_{i j}$ is the transformed reduced stiffness coefficient.

The stress-strain relation of a lamina is rewritten as [23]:

$$
\left\{\begin{array}{l}
\sigma_{x x} \\
\sigma_{x z}
\end{array}\right\}=\left[\begin{array}{ll}
\tilde{Q}_{11} & \\
& \tilde{Q}_{55}
\end{array}\right]\left\{\begin{array}{l}
\varepsilon_{x x} \\
\gamma_{x z}
\end{array}\right\}
$$

where $\tilde{Q}_{i j}$ is the transformed reduced stiffness coefficient and given by:

For anisotropic layer:

$$
\tilde{Q}_{11}=\bar{Q}_{11}-\frac{\bar{Q}_{12} \bar{Q}_{12}}{\bar{Q}_{22}} \quad \tilde{Q}_{55}=\bar{Q}_{55}-\frac{\bar{e}_{25}}{\bar{e}_{24}} \bar{Q}_{45}
$$

For isotropic layer:

$$
\tilde{Q}_{11}=E \quad \tilde{Q}_{55}=G \quad \text {, and } \quad \bar{Q}_{i j}=Q_{i j}
$$

The resultant forces and moments per unit length, $N_{x}$ and $M_{x}$, acting on a lamina are obtained by integrating the stresses in each layer through the lamina thickness as:

$$
\begin{aligned}
& N_{x}=\int_{-h / 2}^{h / 2} \sigma_{x} d z=\sum_{n=1}^{N}\left[\int_{z_{k-1}}^{z_{k}}\left(\sigma_{x}\right)_{k} d z\right] \\
& N_{x z}=\int_{-h / 2}^{h / 2} \sigma_{x z} d z=\sum_{n=1}^{N}\left[\int_{z_{k-1}}^{z_{k}}\left(\sigma_{x z}\right)_{k} d z\right] \\
& M_{x}=\int_{-h / 2}^{h / 2} \sigma_{x} z d z=\sum_{n=1}^{N}\left[\int_{z_{k-1}}^{z_{k}}\left(\sigma_{x}\right)_{k} z d z\right] \\
& M_{x z}=\int_{-h / 2}^{h / 2} \sigma_{x z} z d z=\sum_{n=1}^{N}\left[\int_{z_{k-1}}^{z_{k}}\left(\sigma_{x z}\right)_{k} z d z\right]
\end{aligned}
$$

Substituting by Eqn. (13) into Eqn. (14) and (15) yields: 


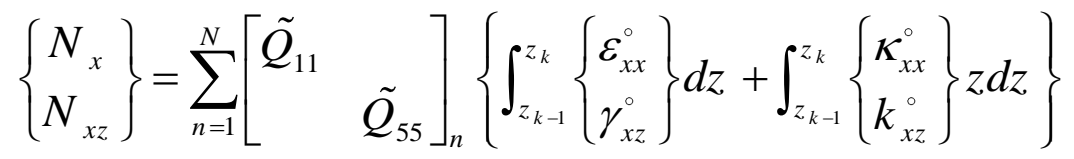

$$
\begin{aligned}
& \text {, and }
\end{aligned}
$$

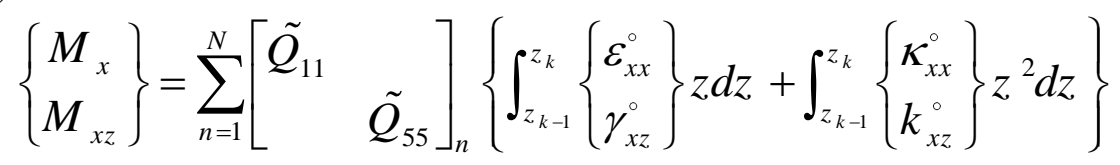

By substituting Eqn. (4) into Eqn. (A-4) yields the stress-strain relation for the lamina as follows:

$$
\left\{\begin{array}{c}
\sigma_{x x} \\
\sigma_{x z}
\end{array}\right\}=\left[\begin{array}{cc}
\tilde{Q}_{11} & 0 \\
0 & \tilde{Q}_{55}
\end{array}\right]\left\{\begin{array}{c}
\varepsilon_{x x}^{\circ}+z k_{x x}^{\circ} \\
\gamma_{x z}^{\circ}
\end{array}\right\}
$$

The mid-plane strains and curvatures are given in terms of forces and moments per unit length as [17]:

$$
\left[\begin{array}{l}
N \\
M
\end{array}\right]=\left[\begin{array}{ll}
A & B \\
B & D
\end{array}\right] \cdot\left[\begin{array}{c}
\varepsilon_{0} \\
\kappa^{0}
\end{array}\right]
$$

where $A_{i j}, B_{i j}$ and $D_{i j}$ represent the elements of the lamina extensional stiffness, coupling stiffness and bending stiffness matrices, respectively, and they are given by:

$$
\begin{aligned}
A_{i j} & =\sum_{k=1}^{N}\left(\tilde{Q}_{i j}\right)\left(z_{k}-z_{k-1}\right), \\
B_{i j} & =\frac{1}{2} \sum_{k=1}^{N}\left(\tilde{Q}_{i j}\right)\left(z_{k}^{2}-z_{k-1}^{2}\right), \text { and } \\
\mathrm{D}_{\mathrm{ij}} & =\frac{1}{3} \sum_{\mathrm{k}=1}^{\mathrm{N}}\left(\tilde{\mathrm{Q}}_{\mathrm{ij}}\right)\left(\mathrm{z}_{\mathrm{k}}^{3}-\mathrm{z}_{\mathrm{k}-1}^{3}\right)_{\mathrm{k}} .
\end{aligned}
$$

\section{Appendix B}

The element load vector is:

$$
\begin{aligned}
& F=\left[\begin{array}{ll}
F_{M} & G
\end{array}\right]^{\prime}
\end{aligned}
$$

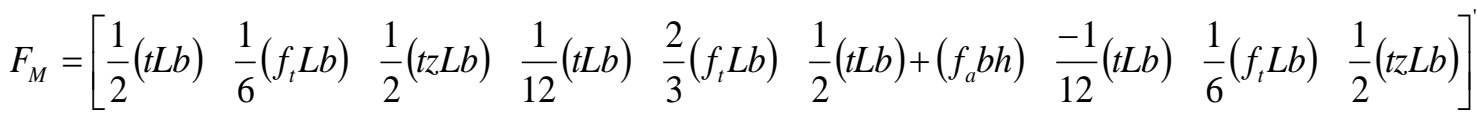

$$
\begin{aligned}
& G=\left[\begin{array}{ll}
\frac{1}{2} \sigma L b & \frac{1}{2} \sigma L b
\end{array}\right]^{\prime}
\end{aligned}
$$

The element stiffness matrix $K_{q q}$ for isotropic Timoshenko Beam is: 


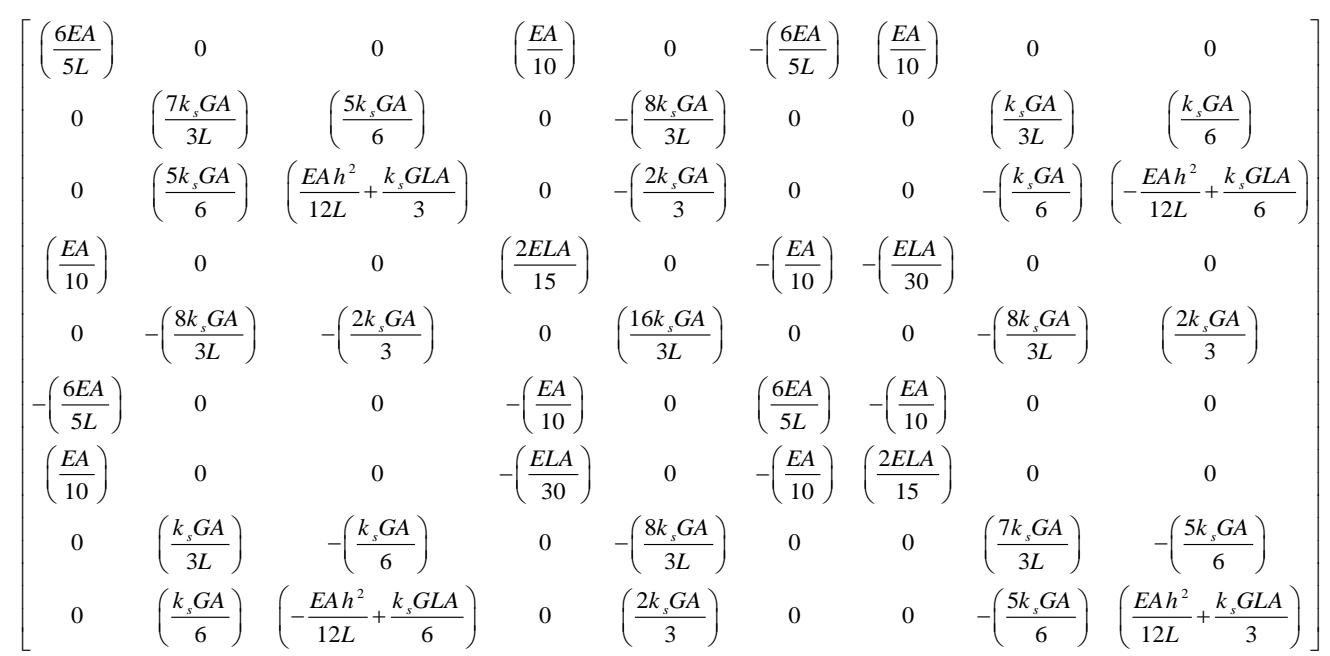

The element stiffness matrix $K_{q q}$ for Anisotropic Timoshenko Beam is:

$\left[\begin{array}{ccccccccc}\frac{6 A_{11} b}{5 L} & 0 & -\frac{B_{11} b}{L} & \frac{A_{11} b}{10} & 0 & -\frac{6 A_{11} b}{5 L} & \frac{A_{11} b}{10} & 0 & \frac{B_{11} b}{L} \\ 0 & \frac{7 k_{\mathrm{s}} A_{55} b}{3 L} & \frac{5 k_{\mathrm{s}} A_{55} b}{6} & 0 & -\frac{8 k_{\mathrm{s}} A_{55} b}{3 L} & 0 & 0 & \frac{k_{\mathrm{s}} A_{55} b}{3 L} & \frac{k_{\mathrm{s}} A_{55} b}{6} \\ -\frac{B_{11} b}{L} & \frac{5 k_{\mathrm{s}} A_{55} b}{6} & \left(\frac{D_{11} b}{L}+\frac{k_{\mathrm{s}} A_{55} L b}{3}\right) & 0 & -\frac{2 k_{\mathrm{s}} A_{55} b}{3} & \frac{B_{11} b}{L} & 0 & -\frac{k_{\mathrm{s}} A_{55} b}{6} & \left(-\frac{D_{11} b}{L}+\frac{k_{\mathrm{s}} A_{55} L b}{6}\right) \\ \frac{A_{11} b}{10} & 0 & 0 & \frac{2 A_{11} L b}{15} & 0 & -\frac{A_{11} b}{10} & -\frac{A_{11} L b}{30} & 0 & 0 \\ 0 & -\frac{8 k_{\mathrm{s}} A_{55} b}{3 L} & -\frac{2 k_{\mathrm{s}} A_{55} b}{3} & 0 & \frac{16 k_{\mathrm{s}} A_{55} b}{3 L} & 0 & 0 & -\frac{8 k_{\mathrm{s}} A_{55} b}{3 L} & \frac{2 k_{\mathrm{s}} A_{55} b}{3} \\ -\frac{6 A_{11} b}{5 L} & 0 & \frac{B_{11} b}{L} & -\frac{A_{11} b}{10} & 0 & \frac{6 A_{11} b}{5 L} & -\frac{A_{11} b}{10} & 0 & -\frac{B_{11} b}{L} \\ \frac{A_{11} b}{10} & 0 & 0 & -\frac{A_{11} L b}{30} & 0 & -\frac{A_{11} b}{10} & \frac{2 A_{11} L b}{15} & 0 & 0 \\ 0 & \frac{k_{\mathrm{s}} A_{55} b}{3 L} & -\frac{k_{\mathrm{s}} A_{55} b}{6} & 0 & -\frac{8 k_{\mathrm{s}} A_{55} b}{3 L} & 0 & 0 & \frac{7 k_{\mathrm{s}} A_{55} b}{3 L} & -\frac{5 k_{\mathrm{s}} A_{55} b}{6} \\ \frac{B_{11} b}{L} & \frac{k_{\mathrm{s}} A_{55} b}{6} & \left(-\frac{D_{11} b}{L}+\frac{k_{\mathrm{s}} A_{55} L b}{6}\right) & 0 & \frac{2 k_{\mathrm{s}} A_{55} b}{3} & -\frac{B_{11} b}{L} & 0 & -\frac{5 k_{\mathrm{s}} A_{55} b}{6} & \left(\frac{D_{11} b}{L}+\frac{k_{\mathrm{s}} A_{55} L b}{3}\right)\end{array}\right]$

The element mass matrix $M_{q q}$ for the Timoshenko Beam is:

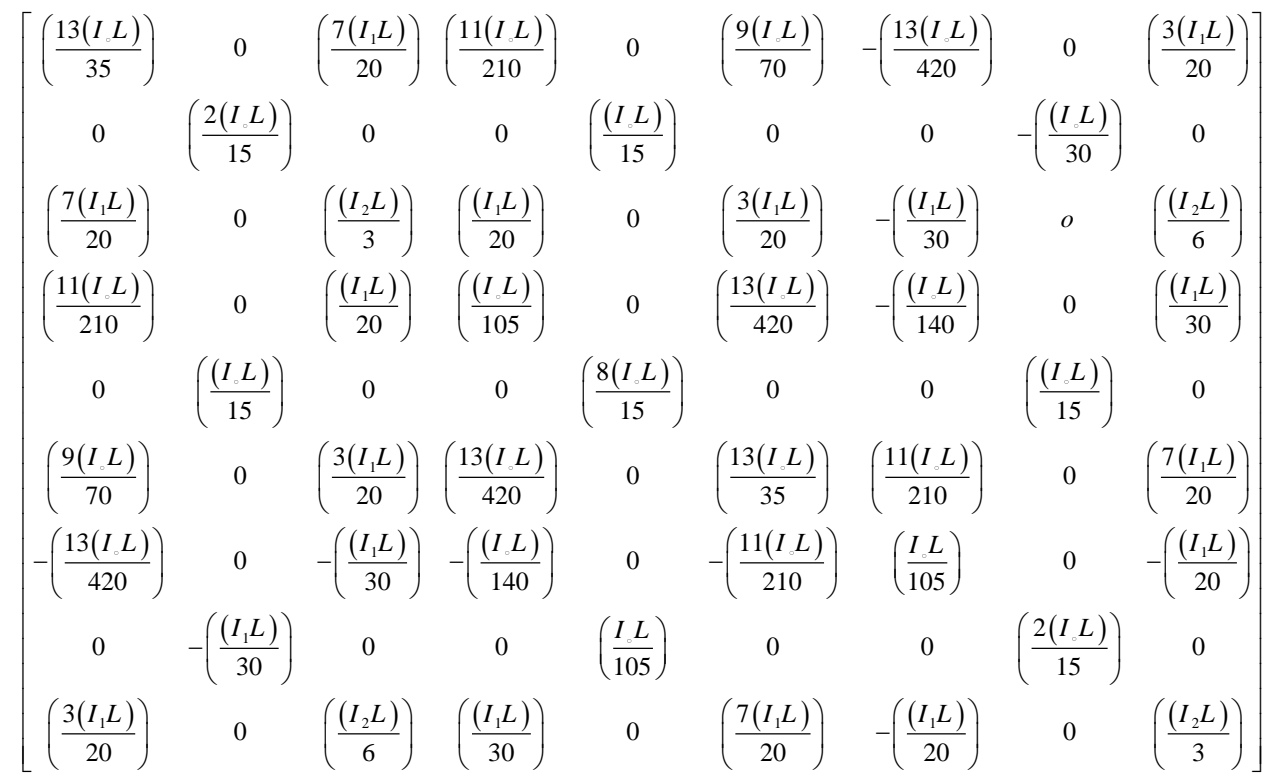


The electro-mechanical coupled stiffness matrices are:

$$
\begin{aligned}
& {\left[K_{q \varphi}\right]=\left[\begin{array}{ccccccccc}
-\frac{1}{2} e_{31} b_{p} & -\frac{5}{6} e_{31} b_{p} & \{\Lambda 1\} & \frac{1}{12} e_{31} L_{p} b_{p} & \frac{2}{3} e_{31} b_{p} & \frac{1}{2} e_{31} b_{p} & -\frac{1}{12} e_{31} L_{p} b_{p} & \frac{1}{6} e_{31} b_{p} & \left\{-\Lambda_{2}\right\} \\
-\frac{1}{2} e_{31} b_{p} & -\frac{1}{6} e_{31} b_{p} & \left\{\Lambda_{2}\right\} & -\frac{1}{12} e_{31} L_{p} b_{p} & -\frac{2}{3} e_{31} b_{p} & \frac{1}{2} e_{31} b_{p} & \frac{1}{12} e_{31} L_{p} b_{p} & \frac{5}{6} e_{31} b_{p} & \left\{-\Lambda_{1}\right\}
\end{array}\right]^{T}} \\
& {\left[K_{\varphi \varphi}\right]=\left[\begin{array}{cc}
-\frac{1}{3} \frac{\varepsilon_{33} L_{p} b_{p}}{h_{p}} & -\frac{1}{6} \frac{\varepsilon_{33} L_{p} b_{p}}{h_{p}} \\
-\frac{1}{6} \frac{\varepsilon_{33} L_{p} b_{p}}{h_{p}} & -\frac{1}{3} \frac{\varepsilon_{33} L_{p} b_{p}}{h_{p}}
\end{array}\right]} \\
& {\left[K_{\varphi q}\right]=\left[\begin{array}{ccccccccc}
-\frac{1}{2} e_{31} b_{p} & -\frac{5}{6} e_{31} b_{p} & \{\Lambda 1\} & \frac{1}{12} e_{31} L_{p} b_{p} & \frac{2}{3} e_{31} b_{p} & \frac{1}{2} e_{31} b_{p} & -\frac{1}{12} e_{31} L_{p} b_{p} & \frac{1}{6} e_{31} b_{p} & \left\{-\Lambda_{2}\right\} \\
-\frac{1}{2} e_{31} b_{p} & -\frac{1}{6} e_{31} b_{p} & \left\{\Lambda_{2}\right\} & -\frac{1}{12} e_{31} L_{p} b_{p} & -\frac{2}{3} e_{31} b_{p} & \frac{1}{2} e_{31} b_{p} & \frac{1}{12} e_{31} L_{p} b_{p} & \frac{5}{6} e_{31} b_{p} & \left\{-\Lambda_{1}\right\}
\end{array}\right]}
\end{aligned}
$$

where

$$
\begin{aligned}
& \Lambda_{1}=\left\{\frac{1}{4} \frac{e_{31} b_{p}}{h_{p}}\left(\left(\frac{h}{2}+h_{p}\right)^{2}-\frac{h^{2}}{4}\right)-\frac{1}{3} e_{31} L_{p} b_{p}\right\} \\
& \Lambda_{2}=\left\{\frac{1}{4} \frac{e_{31} b_{p}}{h_{p}}\left(\left(\frac{h}{2}+h_{p}\right)^{2}-\frac{h^{2}}{4}\right)-\frac{1}{6} e_{31} L_{p} b_{p}\right\}
\end{aligned}
$$

where, $\mathrm{p}$ refers to the piezoelectric layer. 